\title{
The Polar Amplification Model Intercomparison Project (PAMIP) contribution to CMIP6: investigating the causes and consequences of polar amplification
}

\author{
Doug M. Smith ${ }^{1}$, James A. Screen ${ }^{2}$ Clara Deser $^{3}$, Judah Cohen ${ }^{4}$, John C. Fyfe ${ }^{5}$, Javier García-Serrano ${ }^{6,7}$, \\ Thomas Jung ${ }^{8,9}$, Vladimir Kattsov ${ }^{10}$, Daniela Matei ${ }^{11}$, Rym Msadek ${ }^{12}$, Yannick Peings ${ }^{13}$, Michael Sigmond ${ }^{5}$, \\ Jinro Ukita ${ }^{14}$, Jin-Ho Yoon ${ }^{15}$, and Xiangdong Zhang ${ }^{16}$ \\ ${ }^{1}$ Met Office Hadley Centre, Exeter, UK \\ ${ }^{2}$ College of Engineering, Mathematics and Physical Sciences, University of Exeter, Exeter, UK \\ ${ }^{3}$ Climate and Global Dynamics, National Center for Atmospheric Research, Boulder, CO, USA \\ ${ }^{4}$ Atmospheric and Environmental Research, Lexington, MA, USA \\ ${ }^{5}$ Canadian Centre for Climate Modelling and Analysis, Environment and Climate Change Canada, Victoria, \\ British Columbia, Canada \\ ${ }^{6}$ Barcelona Supercomputing Center (BSC), Barcelona, Spain \\ ${ }^{7}$ Group of Meteorology, Universitat de Barcelona, Barcelona, Spain \\ ${ }^{8}$ Alfred Wegener Institute, Helmholtz Centre for Polar and Marine Research, Bremerhaven, Germany \\ ${ }^{9}$ Institute of Environmental Physics, University of Bremen, Bremen, Germany \\ ${ }^{10}$ Voeikov Main Geophysical Observatory, Roshydromet, St. Petersburg, Russia \\ ${ }^{11}$ Max-Planck-Institut für Meteorologie, Hamburg, Germany \\ ${ }^{12}$ CERFACS/CNRS, UMR 5318, Toulouse, France \\ ${ }^{13}$ Department of Earth System Science, University of California Irvine, Irvine, CA, USA \\ ${ }^{14}$ Institute of Science and Technology, Niigata University, Niigata, Japan \\ ${ }^{15}$ Gwangju Institute of Science and Technology, School of Earth Sciences and Environmental Engineering, \\ Gwangju, South Korea \\ ${ }^{16}$ International Arctic Research Center, University of Alaska Fairbanks, Fairbanks, AK, USA
}

Correspondence: Doug M. Smith (doug.smith@metoffice.gov.uk)

Received: 23 March 2018 - Discussion started: 6 June 2018

Revised: 12 December 2018 - Accepted: 8 January 2019 - Published: 25 March 2019

\begin{abstract}
Polar amplification - the phenomenon where external radiative forcing produces a larger change in surface temperature at high latitudes than the global average - is a key aspect of anthropogenic climate change, but its causes and consequences are not fully understood. The Polar Amplification Model Intercomparison Project (PAMIP) contribution to the sixth Coupled Model Intercomparison Project (CMIP6; Eyring et al., 2016) seeks to improve our understanding of this phenomenon through a coordinated set of numerical model experiments documented here. In particular, PAMIP will address the following primary questions: (1) what are the relative roles of local sea ice and remote sea surface temperature changes in driving polar amplifica-
\end{abstract}

tion? (2) How does the global climate system respond to changes in Arctic and Antarctic sea ice? These issues will be addressed with multi-model simulations that are forced with different combinations of sea ice and/or sea surface temperatures representing present-day, pre-industrial and future conditions. The use of three time periods allows the signals of interest to be diagnosed in multiple ways. Lower-priority tier experiments are proposed to investigate additional aspects and provide further understanding of the physical processes. These experiments will address the following specific questions: what role does ocean-atmosphere coupling play in the response to sea ice? How and why does the atmospheric response to Arctic sea ice depend on the pattern of sea ice forc- 
ing? How and why does the atmospheric response to Arctic sea ice depend on the model background state? What have been the roles of local sea ice and remote sea surface temperature in polar amplification, and the response to sea ice, over the recent period since 1979? How does the response to sea ice evolve on decadal and longer timescales?

A key goal of PAMIP is to determine the real-world situation using imperfect climate models. Although the experiments proposed here form a coordinated set, we anticipate a large spread across models. However, this spread will be exploited by seeking "emergent constraints" in which model uncertainty may be reduced by using an observable quantity that physically explains the intermodel spread. In summary, PAMIP will improve our understanding of the physical processes that drive polar amplification and its global climate impacts, thereby reducing the uncertainties in future projections and predictions of climate change and variability.

\section{Introduction}

Polar amplification refers to the phenomenon in which zonally averaged surface temperature changes in response to climate forcings are larger at high latitudes than the global average. Polar amplification, especially in the Arctic, is a robust feature of global climate model simulations of recent decades (Bindoff et al., 2013) and future projections driven by anthropogenic emissions of carbon dioxide (Fig. 1, Collins et al., 2013). Polar amplification over both poles is also seen in simulations of paleo-climate periods driven by solar or natural carbon cycle perturbations (Masson-Delmotte et al., 2013).

Observations over recent decades (Fig. 2) suggest that Arctic amplification is already occurring: recent temperature trends in the Arctic are about twice the global average (Serreze et al., 2009; Screen and Simmonds, 2010; Cowtan and Way, 2013), and Arctic sea ice extent has declined at an average rate of around $4 \% \mathrm{decade}^{-1}$ annually and more than $10 \%$ decade $^{-1}$ during the summer (Vaughan et al., 2013). Climate model simulations of the Arctic are broadly consistent with the observations (Fig. 2). However, there is a large intermodel spread in temperature trends (Bindoff et al., 2013), the observed rate of sea ice loss is larger than most model simulations (Stroeve et al., 2012), and the driving mechanisms are not well understood (discussed further below). Antarctic amplification has not yet been observed (Fig. 2). Indeed, Antarctic sea ice extent has increased slightly over recent decades (Vaughan et al., 2013) in contrast to most model simulations (Bindoff et al., 2013), and understanding recent trends represents a key challenge (Turner and Comiso 2017). Nevertheless, Antarctic amplification is expected in the future in response to further increases in greenhouse gases but is likely to be delayed relative to the Arctic due to strong heat uptake in the Southern Ocean (Collins et al., 2013; Armour et al., 2016). There is mounting evidence

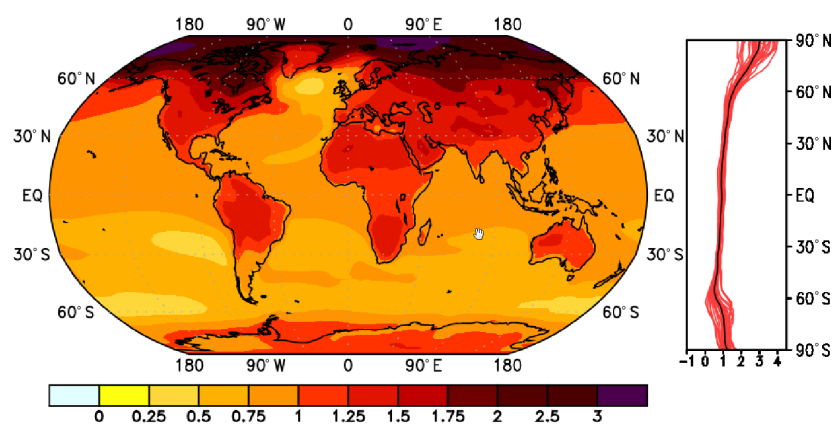

Figure 1. Polar amplification in projections of future climate change. Temperature change patterns are derived from 31 CMIP5 model projections driven by RCP8.5, scaled to $1^{\circ} \mathrm{C}$ of global mean surface temperature change. The patterns have been calculated by computing 20-year averages at the end of the 21st (2080-2099) and 20th (1981-2000) centuries, taking their difference and normalising it, grid point by grid point, by the global average temperature change. Averaging across models is performed before normalisation, as recommended by Hind et al. (2016). The colour scale represents degrees Celsius per $1^{\circ} \mathrm{C}$ of global average temperature change. Zonal means of the geographical patterns are shown for each individual model (red) and for the multi-model ensemble mean (black).

that polar amplification will affect the global climate system by altering the atmosphere and ocean circulations, but the precise details and physical mechanisms are poorly understood (discussed further below).

The Polar Amplification Model Intercomparison Project (PAMIP) will investigate the causes and global consequences of polar amplification, through creation and analysis of an unprecedented set of coordinated multi-model experiments and strengthened international collaboration. The broad scientific objectives aim to

- provide new multi-model estimates of the global climate response to Arctic and Antarctic sea ice changes;

- determine the robustness of the responses between different models and the physical reasons for differences;

- improve our physical understanding of the mechanisms causing polar amplification and its global impacts; and

- harness increased process understanding and new multimodel ensembles to constrain projections of future climate change in the polar regions and associated global climate impacts.

PAMIP will directly contribute to the World Climate Research Programme (WCRP) Grand Challenges on Nearterm Climate Prediction, Melting Ice and Global Consequences, and Weather and Climate Extremes, and addresses all three of the sixth Coupled Model Intercomparison Project (CMIP6; Eyring et al., 2016) scientific questions: 
(a) Observations

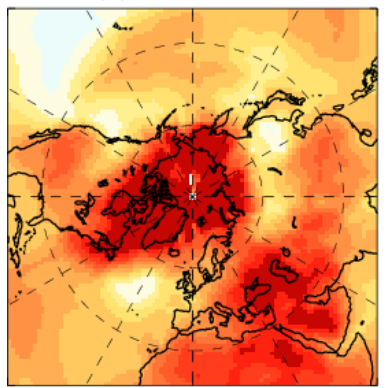

(c) Models

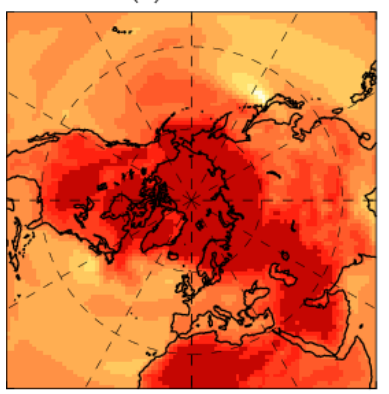

$-0.5$ (d) Models

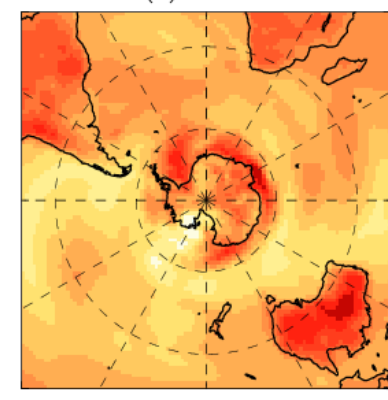

0.5

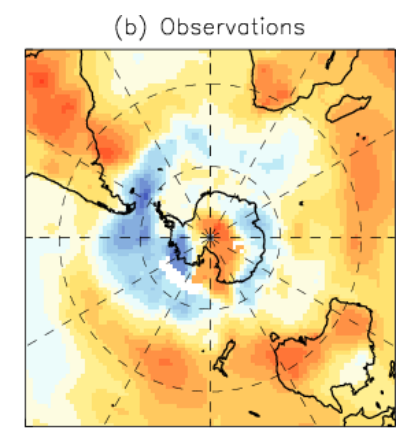

Figure 2. Recent Arctic and Antarctic temperature trends $\left({ }^{\circ} \mathrm{C}\right.$ decade $\left.^{-1}\right)$ in $(\mathbf{a}, \mathbf{b})$ observations and $(\mathbf{c}, \mathbf{d})$ model simulations. Linear trends are shown for the 30-year period (1988 to 2017). Observations are taken as the average of HadCRUT4 (Morice et al., 2012), NASA-GISS (Hansen et al., 2010) and NCDC (Karl et al., 2015). Model trends are computed as the average from 25 CMIP5 model simulations driven by historical and $\mathrm{RCP} 4.5$ radiative forcings.

1. How does the Earth system respond to forcing? This will be addressed through coordinated multi-model experiments to understand the causes and consequences of polar amplification.

2. What are the origins and consequences of systematic model biases? Specific experiments are proposed to investigate the role of model biases in the atmospheric response to sea ice.

3. How can we assess future climate changes given climate variability, predictability and uncertainties in scenarios? Analysis of PAMIP experiments will focus on process understanding in order to constrain future projections.

This paper describes the motivation for PAMIP and documents the proposed model experiments and suggested analysis procedure. An overview of the causes and consequences of polar amplification is given in Sects. 2 and 3 before outlining the need for coordinated model experiments in Sect. 4. The proposed PAMIP experiments and analysis are documented in Sect. 5 and the data request is described in Sect. 6. Interactions with other Model Intercomparison
Projects (MIPs) are discussed in Sect. 7. A summary is provided in Sect. 8, and data availability is described in Sect. 9. Details of the forcing data are given in Appendix A, and technical details for running the experiments are given in Appendix B.

\section{Causes of polar amplification}

Polar amplification arises both from the pattern of radiative forcing (Huang et al., 2017) and several feedback mechanisms that operate at both low and high latitudes (Taylor et al., 2013; Pithan and Mauritsen, 2014). The most well established of these is the surface albedo feedback at high latitudes (Manabe and Stouffer, 1994; Hall, 2004) in which melting of highly reflective sea ice and snow regions results in increased absorption of solar radiation which amplifies the warming. However, lapse rate and Planck feedbacks play a larger role in climate model simulations of Arctic amplification than the surface albedo feedback (Pithan and Mauritsen, 2014). Lapse rate feedback is negative at lower latitudes where the upper troposphere is heated by latent heat released by rising air parcels but becomes positive at high latitudes where the more stable atmosphere restricts local surface-driven warming to low altitudes. Hence, lapse rate feedback directly drives polar amplification by acting to reduce the warming at low latitudes and increase the warming at high latitudes. Planck feedback is negative everywhere and opposes global warming by emission of long-wave radiation. However, it operates more strongly at warmer lower latitudes and therefore contributes to polar amplification. Other feedbacks are also potentially important in controlling temperature trends in polar regions, including water vapour (Graversen and Wang, 2009) and clouds (Vavrus, 2004), and changes in heat transport in the atmosphere (Manabe and Wetherald, 1980) and ocean (Khodri et al., 2001; Holland and Bitz, 2003; Spielhagen et al., 2011). Although some of these may operate more strongly at lower latitudes, thereby opposing polar amplification (Pithan and Mauritsen, 2014), they are important in controlling the overall temperature trends and hence the magnitude of polar amplification.

Factors other than anthropogenic increases in greenhouse gases (GHGs) modulated by the feedbacks outlined above have also contributed to recent temperature trends, potentially enhancing or inhibiting the observed rates of polar amplification. Arctic warming rates over the last century have likely been modulated by changes in solar radiation, volcanic eruptions and anthropogenic aerosol emissions (Overpeck et al., 1997; Fyfe et al., 2013; Acosta Navarro et al., 2016; Gagné et al., 2017), and by decadal timescale variations in Atlantic and Pacific sea surface temperatures (Chylek et al., 2009; Ding et al., 2014, 2017; Tokinaga et al., 2017), referred to here as Pacific decadal variability (PDV) and Atlantic multidecadal variability (AMV). Recent Antarctic temperature and sea ice trends (Fig. 2) have likely been strongly influ- 
enced by changes in atmospheric circulation (Turner et al., 2015; Raphael et al., 2015; Jones et al., 2016b), notably an increase in the Southern Annular Mode (SAM) and a deepening of the Amundsen Sea Low (ASL). The SAM increase, especially during austral summer, has been linked to ozone depletion (Thompson and Solomon, 2002), but its role in driving warming of the Antarctic Peninsula, which peaks in winter and spring, is unclear (Smith and Polvani, 2017). The deepening of the ASL has likely been influenced by both PDV (Purich et al., 2016; Schneider et al., 2015; Schneider and Deser, 2017) and AMV (Li et al., 2014). Freshening of Antarctic surface waters from melting ice shelves may also have influenced recent Antarctic sea ice and temperature trends (Bintanja et al., 2013), though the magnitude of this effect is uncertain (Swart and Fyfe, 2013).

\section{Consequences of polar amplification}

Polar amplification will affect the melting of polar ice sheets and hence sea level rise, and the rate of carbon uptake in the polar regions. These impacts are investigated by the Ice Sheet Model Intercomparison Project (Nowicki et al., 2016) and the Coupled Climate-Carbon Cycle Model Intercomparison Project (Jones et al., 2016a), respectively. PAMIP, described here, will focus on the impacts of sea ice changes on the global climate system through changes in the atmosphere and ocean circulation. This is an area of intensive scientific interest and debate, as summarised in several recent reviews (Cohen et al., 2014; Vihma, 2014; Walsh, 2014; Barnes and Screen, 2015; Overland et al., 2015, Screen et al., 2018). A number of hypothesised consequences of a warming Arctic have been proposed based on observations, including changes in the behaviour of the polar jet stream (e.g. Francis and Vavrus, 2012), that could potentially give rise to more persistent and extreme weather events. Arctic warming has also been proposed as a cause of decadal cooling trends over Eurasia (Liu et al., 2012; Mori et al., 2014; Kretschmer et al., 2017), in what has been referred to as the warm Arcticcold continents pattern (Overland et al., 2011; Cohen et al., 2013). However, determining causality solely from observations is an intractable problem. For this reason, model experiments with reduced sea ice have been extensively used - but to date, with little coordination between modelling groups in an attempt to better isolate the response to sea ice loss and understand the causal mechanisms. Such experiments tend to broadly agree on the local thermodynamic response but diverge considerably on the dynamical response (e.g. Liu et al., 2012; Mori et al., 2014; Sun et al., 2016; Ogawa et al., 2018). A key area of uncertainty is the atmospheric circulation changes in responses to Arctic warming. By definition, polar amplification will reduce the Equator-to-pole surface temperature gradient, potentially weakening the midlatitude westerly winds and promoting a negative Arctic Oscillation (AO) or North Atlantic Oscillation (NAO). However, this dynamic response may be opposed by a local thermodynamic low-pressure response to Arctic warming that acts to strengthen the midlatitude westerlies (Smith et al., 2017), and the overall response is unclear (Deser et al., 2015; Shepherd, 2016). Since the remote consequences of polar amplification are to a large extent governed by changes in the atmospheric circulation, it is of critical importance to attempt to constrain the circulation response to polar amplification through collaborative modelling activities. The response to Antarctic sea ice has received far less attention. Some studies simulate an equatorward shift of the midlatitude tropospheric jet in response to reduced Antarctic sea ice (Raphael et al., 2011; Bader et al., 2013; Smith et al., 2017; England et al., 2018), but it is unclear whether this relationship will continue to hold in future as the sea ice retreats (Kidston et al., 2011). Polar amplification will also drive changes in the ocean, potentially giving rise to global climate impacts. For example, reduced Arctic sea ice may weaken the Atlantic meridional overturning circulation (Sévellec et al., 2017; Suo et al., 2017), and increased warming of the Northern Hemisphere relative to the Southern Hemisphere may shift the Intertropical Convergence Zone (ITCZ) (Chiang and Bitz, 2005) affecting Sahel rainfall and tropical storm activity (Smith et al., 2017), and Californian drought (Cvijanovic et al., 2017). However, the extent to which the latter impacts are mitigated by changes in ocean heat transport convergence is uncertain (Tomas et al., 2016).

\section{The need for coordinated model experiments}

It is clear from the discussion in Sects. 2 and 3 that both the causes and consequences of polar amplification are uncertain. CMIP6 (Eyring et al., 2016) provides an unprecedented opportunity to improve our understanding of climate change and variability in general, and several CMIP6 MIPs will provide valuable information on the causes and consequences of polar amplification in particular, as discussed in Sect. 7. PAMIP will complement the other CMIP6 MIPs by providing coordinated model experiments that are specifically designed to investigate the physical mechanisms driving polar amplification and the climate system's response to changes in sea ice. Improved understanding of the physical processes gained through PAMIP will enable uncertainties in future polar amplification and associated climate impacts to be reduced.

A key uncertainty regarding the causes of polar amplification is the relative role of local processes that directly affect the surface energy budget and remote processes that affect the poleward heat transport. Local processes are likely to induce a response that is strongest near to the surface (Screen and Simmonds, 2010), whereas changes in atmospheric heat transport may affect the mid-troposphere more strongly (Graverson et al., 2008). Observations of recent Arctic temperature trends show warming throughout the lower 


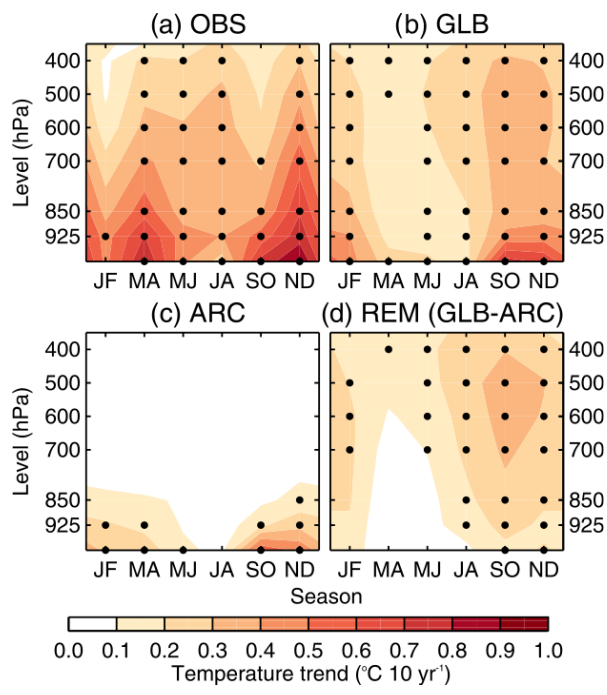

Figure 3. Local and remote drivers of Arctic warming. (a) Vertical and seasonal structure of the reanalysis ensemble-mean (OBS) Arctic-mean temperature trends (1979-2008). (b-d) As in panel (a) but for the model ensemble-mean simulations forced by observed changes in global SST and SIC (GLB), observed changes only in Arctic SIC and associated SST (ARC), and their difference (REM), respectively. Black dots show trends that are statistically significant at the $95 \%$ level $(p<0.05)$. These experiments enable the relative contributions of local (ARC) and remote (REM) processes to Arctic trends to be assessed, giving insight into the driving mechanisms. Source: Screen et al. (2012)

troposphere to mid-troposphere (Fig. 3a), suggesting that both local and remote processes could be important, but assessing their relative roles is not possible from observations alone. Model experiments in which remote sea surface temperature (SST) and sea ice concentration (SIC) changes are imposed separately (Kumar et al., 2010; Screen et al., 2012; Perlwitz et al., 2015) enable the contributions from local and remote processes to be quantified (Fig. 3b-d) and will be a core component of PAMIP.

It is also not possible to diagnose the climate system response to sea ice from observations alone. This is illustrated in Fig. 4, which compares the winter mean sea level response to reduced Arctic sea ice inferred from lagged regression with the simulated response obtained in model experiments driven by changes in sea ice (Smith et al., 2017). Lagged regression shows a pattern that projects onto a negative NAO in both the observations and in atmosphere model experiments driven by observed SIC and SST (Fig. 4a and b). These regressions imply a negative NAO response to reduced Arctic sea ice (e.g. Liu et al., 2012). However, the actual response to reduced Arctic sea ice determined from specific experiments using the same model is a weak positive NAO (Fig. 4c). This suggests that the model response (Fig. 4b) is driven by changes in SST rather than SIC. Hence, although statistical analysis can provide useful insights, the results can (a) Obs regression

(b) AMIP regression

(c) AMIP response

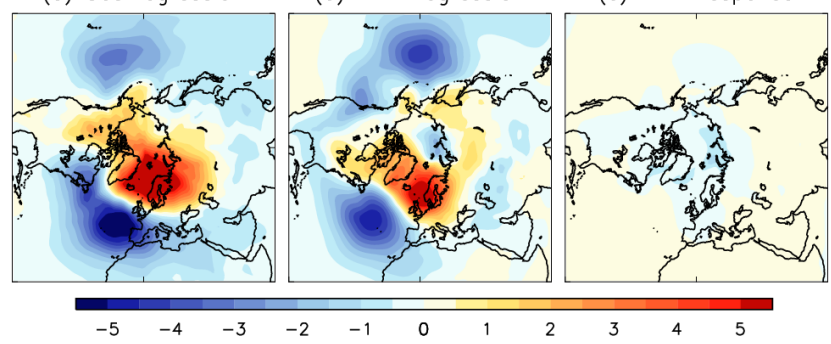

Figure 4. Inability to diagnose atmospheric response to sea ice from observations alone. Linear regression between autumn (SeptemberNovember) Arctic sea ice extent and winter (December-February) mean sea level pressure (reversed sign) in (a) observations and (b) atmosphere model experiments forced by observed SIC and SST following the Atmosphere Model Intercomparison Project (AMIP) protocol. All time series were linearly detrended and cover the period December 1979 to November 2009. (c) Winter mean sea level response to reduced sea ice in atmospheric model experiments (scaled by the average autumn sea ice extent reduction). Units are $\mathrm{hPa}$ per million $\mathrm{km}^{2}$. Source: Smith et al. (2017).

sometimes be misleading and need to be supported by dedicated model experiments. However, modelling studies currently simulate a full spectrum of NAO responses to reduced Arctic sea ice including negative NAO (Honda et al., 2009; Seierstad and Bader, 2009; Mori et al., 2014; Kim et al., 2014; Deser et al., 2015; Nakamura et al., 2015), positive NAO (Singarayer et al., 2006; Strey et al., 2010; Orsolini et al., 2012; Rinke et al., 2013; Cassano et al., 2014; Screen et al., 2014), little response (Screen et al., 2013; Petrie et al., 2015; Blackport and Kushner, 2016) and a response that depends on the details of the forcing (Alexander et al., 2004; Petoukhov and Semenov, 2010; Peings and Magnusdottir, 2014; Sun et al., 2015; Pedersen et al., 2016; Chen et al., 2016). There are many potential reasons for the different responses found in modelling studies, including the following:

- Differences in the magnitude of the forcing. Some studies have investigated the response to sea ice perturbations typical of the present day and near future (e.g. Chen et al., 2016; Smith et al., 2017), while others have investigated the impact of larger changes expected towards the end of the century (e.g. Deser et al., 2016; Blackport and Kushner, 2016). Furthermore, interpreting the impact of differences in the magnitude of the forcing is particularly difficult because the relationship could be non-linear (Petoukhov and Semenov, 2010; Peings and Magnusdottir, 2014; Semenov and Latif, 2015; Chen et al., 2016).

- Differences in the pattern of forcing. Studies have demonstrated that the response is sensitive to the pattern of sea ice anomalies. For example, Sun et al. (2015) obtained opposite responses in the northern polar vortex to sea ice forcing from the Pacific and Atlantic sectors. 
Furthermore, the responses to regional sea ice anomalies do not add linearly (Screen, 2017), complicating their interpretation.

- How the forcing is applied. Changes in sea ice can be imposed in different ways in coupled models, for example, by nudging the model to the required state (e.g. Smith et al., 2017; McCusker et al., 2017), or by changing the fluxes of energy in order to melt some of the sea ice (e.g. Deser et al., 2016; Blackport and Kushner, 2016). The impact of these different approaches is not clear, but they could potentially contribute to the spread of results.

- Additional forcings. Isolating the response to sea ice changes can be complicated if additional forcings are imposed. For example, greenhouse-gas-induced warming of the tropical troposphere tends to increase the Equator-to-pole temperature gradient in the midtroposphere and oppose the impact of sea ice (Deser et al., 2015; Blackport and Kushner, 2017; Oudar et al., 2017). Hence, additional steps are needed to isolate the impacts of sea ice in experiments that also include other forcings (e.g. McCusker et al., 2017).

- Different models. The response can be very sensitive to the model used. For example, Sun et al. (2015) obtained opposite responses in the winter polar vortex in identical forcing experiments with two different models: one with a well-resolved stratosphere and one without. García-Serrano et al. (2017) further discuss the diversity of potential Arctic-midlatitude linkages found in coupled models.

- Atmosphere/ocean coupling. Although many studies have used atmosphere-only models, changes in Arctic sea ice can influence SSTs surrounding the ice pack and also in remote regions, including the tropics (e.g. Deser et al., 2015; Tomas et al., 2016; Smith et al., 2017). Coupled models are essential to simulate these effects and may also amplify the winter midlatitude wind response to Arctic sea ice (Deser et al., 2016).

- Background state. Identical experiments with the same model but with different background states induced by different SST biases can produce opposite NAO responses (Smith et al., 2017). Furthermore, responses may not be robust across experiments due to strong nonlinearities in the system, which can depend on the background state (Chen et al., 2016).

- Land surface. Snow cover can also influence the atmospheric circulation (Cohen and Entekhabi, 1999; Gastineau et al., 2017), although models appear to underestimate the effects (Furtado et al., 2015). Differences in snow cover could therefore contribute to differences in modelled responses to sea ice.
- Low signal-to-noise ratio. The atmospheric response to Arctic sea ice simulated by models is typically small compared to internal variability so that a large ensemble of simulations is required to obtain robust signals (e.g. Screen et al., 2014; Mori et al., 2014; Sun et al., 2016). Some of the different responses reported in the literature could therefore arise from sampling errors. If the low signal-to-noise ratio in models is correct, then the response to Arctic sea ice could be overwhelmed by internal variability (McCusker et al., 2016). However, the signal-to-noise ratio in seasonal forecasts of the NAO is too small in models (Eade et al., 2014; Scaife et al., 2014; Dunstone et al., 2016), suggesting that the magnitude of the simulated response to sea ice could also be too small.

PAMIP seeks to reduce these sources of differences since all simulations will follow the same experimental protocol, allowing the different model responses to be better understood. Additional experiments will also focus on understanding the roles of coupling, the background state and the pattern of forcing.

\section{PAMIP experiments and analysis plan}

Coordinated model experiments in PAMIP will address the following primary questions:

1. What are the relative roles of local sea ice and remote sea surface temperature changes in driving polar amplification?

2. How does the global climate system respond to changes in Arctic and Antarctic sea ice?

These questions will be answered by taking differences between numerical model simulations that are forced with different combinations of SST and/or SIC (Table 1) representing present-day (pd), pre-industrial (pi) and future (fut, $2^{\circ}$ warming) conditions. Pairs of simulations with the same SSTs but different SICs provide estimates both of the contribution of sea ice changes to polar amplification and of the climate response to sea ice changes. Pairs of simulations with the same SICs but different SSTs provide estimates of the contribution of SST changes to polar amplification. The use of three periods allows the signals of interest to be diagnosed in multiple ways. Details of the forcing fields are given in Appendix A, and example SIC and SST forcing fields are shown in Figs. 5 and 6 for the Arctic and Figs. 7 and 8 for the Antarctic. Various definitions of polar amplification have been used in past studies and the precise values obtained are sensitive to the definition applied (Hind et al., 2016). We encourage polar amplification to be defined as the ratio of polar warming (poleward of $60^{\circ}$ in each hemisphere) to globalmean warming. Also, following Hind et al. (2016), we advocate for the amplification ratio to be calculated separately for 
Table 1. PAMIP-coordinated model experiments. The contributions of local sea ice and remote SST to polar amplification, and the response to sea ice, will be diagnosed from atmosphere-only and coupled atmosphere-ocean model experiments using different combinations of SST and SIC representing present-day (pd), pre-industrial (pi) and future (fut, representing $2^{\circ}$ warming) conditions. The signals of interest are obtained by differencing experiments, as shown in Table 2. Further details are given in Appendix B. The prefix "pa" denotes partially coupled experiments that are unique to PAMIP. We stress that the ensemble size is the minimum required and encourage groups to submit more members if possible.

\begin{tabular}{|c|c|c|c|c|c|c|c|}
\hline No. & $\begin{array}{l}\text { Experiment } \\
\text { name }\end{array}$ & Description & Notes & Tier & $\begin{array}{l}\text { Start } \\
\text { year }\end{array}$ & $\begin{array}{l}\text { Number } \\
\text { of years }\end{array}$ & $\begin{array}{l}\text { Minimum } \\
\text { ensemble size }\end{array}$ \\
\hline \multicolumn{8}{|c|}{ 1. Atmosphere-only time slice experiments } \\
\hline 1.1 & pdSST-pdSIC & $\begin{array}{l}\text { Time slice forced by climatological } \\
\text { monthly mean SST and SIC for the } \\
\text { present day (pd) }\end{array}$ & $\begin{array}{l}\text { Present-day SST and } \\
\text { SIC }\end{array}$ & 1 & 2000 & $1^{2}$ & 100 \\
\hline 1.2 & piSST-piSIC & $\begin{array}{l}\text { Time slice forced by climatological } \\
\text { monthly mean SST and SIC for pre- } \\
\text { industrial (pi) conditions } 3\end{array}$ & $\begin{array}{l}\text { Pre-industrial SST and } \\
\text { SIC }\end{array}$ & 2 & 2000 & 1 & 100 \\
\hline 1.3 & piSST-pdSIC & $\begin{array}{l}\text { Time slice forced by pi SST and pd } \\
\text { SIC }^{3}\end{array}$ & \multirow{2}{*}{$\begin{array}{l}\text { Different SST relative } \\
\text { to } 1.1 \text { to investigate the } \\
\text { role of SSTs in polar } \\
\text { amplification }\end{array}$} & 1 & 2000 & 1 & 100 \\
\hline 1.4 & futSST-pdSIC & $\begin{array}{l}\text { Time slice forced by pd SIC and fu- } \\
\text { ture SST representing } 2^{\circ} \text { global } \\
\text { warming (fut) }\end{array}$ & & 2 & 2000 & 1 & 100 \\
\hline 1.5 & $\begin{array}{l}\text { pdSST- } \\
\text { piArcSIC }\end{array}$ & $\begin{array}{l}\text { Time slice forced by pd SST and pi } \\
\text { Arctic SIC }\end{array}$ & \multirow{2}{*}{$\begin{array}{l}\text { Different Arctic SIC } \\
\text { relative to } 1.1 \text { to in- } \\
\text { vestigate the impacts of } \\
\text { present-day and future } \\
\text { Arctic sea ice and the } \\
\text { role of Arctic SIC in } \\
\text { polar amplification }\end{array}$} & 1 & 2000 & 1 & 100 \\
\hline 1.6 & $\begin{array}{l}\text { pdSST- } \\
\text { futArcSIC }\end{array}$ & $\begin{array}{l}\text { Time slice forced by pd SST and fut } \\
\text { Arctic SIC }\end{array}$ & & 1 & 2000 & 1 & 100 \\
\hline 1.7 & $\begin{array}{l}\text { pdSST- } \\
\text { piAntSIC }\end{array}$ & $\begin{array}{l}\text { Time slice forced by pd SST and pi } \\
\text { Antarctic SIC }\end{array}$ & \multirow{2}{*}{$\begin{array}{l}\text { Different Antarctic SIC } \\
\text { relative to } 1.1 \text { to in- } \\
\text { vestigate the impacts of } \\
\text { present-day and future } \\
\text { Antarctic sea ice and } \\
\text { the role of Antarctic } \\
\text { SIC in polar amplifica- } \\
\text { tion }\end{array}$} & 1 & 2000 & 1 & 100 \\
\hline 1.8 & $\begin{array}{l}\text { pdSST- } \\
\text { futAntSIC }\end{array}$ & $\begin{array}{l}\text { Time slice forced by pd SST and fut } \\
\text { Antarctic SIC }\end{array}$ & & 1 & 2000 & 1 & 100 \\
\hline 1.9 & $\begin{array}{l}\text { pdSST- } \\
\text { pdSICSIT }\end{array}$ & $\begin{array}{l}\text { Time slice forced by pd sea ice } \\
\text { thickness (SIT) in addition to SIC } \\
\text { and SST }\end{array}$ & $\begin{array}{l}\text { Investigate the impacts } \\
\text { of sea ice thickness } \\
\text { changes }\end{array}$ & 3 & 2000 & 1 & 100 \\
\hline 1.10 & $\begin{array}{l}\text { pdSST- } \\
\text { futArcSICSIT }\end{array}$ & $\begin{array}{l}\text { Time slice forced by pd SST and fut } \\
\text { Arctic SIC and SIT }\end{array}$ & $\begin{array}{l}\text { Investigate the impacts } \\
\text { of sea ice thickness } \\
\text { changes }\end{array}$ & 3 & 2000 & 1 & 100 \\
\hline \multicolumn{8}{|c|}{ 2. Coupled ocean-atmosphere time slice experiments } \\
\hline 2.1 & pa-pdSIC & $\begin{array}{l}\text { Coupled time slice constrained by } \\
\text { pd SIC } 2,4,5\end{array}$ & & 2 & 2000 & 1 & 100 \\
\hline 2.2 & pa-piArcSIC & $\begin{array}{l}\text { Coupled time slice with pi Arctic } \\
\text { SIC }^{3}\end{array}$ & $\begin{array}{l}\text { As } 1.5 \text { and } 1.6 \text { but with } \\
\text { coupled model }\end{array}$ & 2 & 2000 & 1 & 100 \\
\hline 2.3 & pa-futArcSIC & $\begin{array}{l}\text { Coupled time slice with fut } \\
\text { ArcticSIC }^{3}\end{array}$ & & 2 & 2000 & 1 & 100 \\
\hline
\end{tabular}


Table 1. Continued.

\begin{tabular}{|c|c|c|c|c|c|c|c|}
\hline No. & $\begin{array}{l}\text { Experiment } \\
\text { name }\end{array}$ & Description & Notes & Tier & $\begin{array}{l}\text { Start } \\
\text { year }\end{array}$ & $\begin{array}{l}\text { Number } \\
\text { of years }\end{array}$ & $\begin{array}{c}\text { Minimum } \\
\text { ensemble size }\end{array}$ \\
\hline 2.4 & pa-piAntSIC & $\begin{array}{l}\text { Coupled time slice with pi Antarctic } \\
\text { SIC }^{3}\end{array}$ & \multirow[t]{2}{*}{$\begin{array}{l}\text { As } 1.7 \text { and } 1.8 \text { but with } \\
\text { coupled model }\end{array}$} & 2 & 2000 & 1 & 100 \\
\hline 2.5 & pa-futAntSIC & $\begin{array}{l}\text { Coupled time slice with fut Antarctic } \\
\text { SIC }^{3}\end{array}$ & & 2 & 2000 & 1 & 100 \\
\hline \multicolumn{8}{|c|}{ 3. Atmosphere-only time slice experiments to investigate regional forcing } \\
\hline 3.1 & $\begin{array}{l}\text { pdSST- } \\
\text { futOkhotskSIC }\end{array}$ & $\begin{array}{l}\text { Time slice forced by pd SST and fut } \\
\text { Arctic SIC only in the Sea of Okhotsk }\end{array}$ & \multirow{2}{*}{$\begin{array}{l}\text { Investigate how the at- } \\
\text { mospheric response de- } \\
\text { pends on the pattern of } \\
\text { Arctic sea ice forcing }\end{array}$} & 3 & 2000 & 1 & 100 \\
\hline 3.2 & $\begin{array}{l}\text { pdSST- } \\
\text { futBKSeasSIC }\end{array}$ & $\begin{array}{l}\text { Time slice forced by pd SST and fut } \\
\text { Arctic SIC only in the Barents/Kara } \\
\text { seas }\end{array}$ & & 3 & 2000 & 1 & 100 \\
\hline
\end{tabular}

4. Atmosphere-only time slice experiments to investigate the role of the background state

\begin{tabular}{|c|c|c|c|c|c|c|c|}
\hline 4.1 & $\begin{array}{l}\text { modelSST- } \\
\text { pdSIC }\end{array}$ & $\begin{array}{l}\text { Time slice forced by pd SIC and pd } \\
\text { SST from coupled model ( } 2.1) \text { rather } \\
\text { than observations }\end{array}$ & \multirow{2}{*}{$\begin{array}{l}\text { In conjunction with ex- } \\
\text { periments } 1 \text { and } 2 \text {, iso- } \\
\text { late the effects of the } \\
\text { background state from } \\
\text { the effects of coupling }\end{array}$} & 3 & 2000 & 1 & 100 \\
\hline 4.2 & $\begin{array}{l}\text { modelSST- } \\
\text { futArcSIC }\end{array}$ & $\begin{array}{l}\text { Time slice forced by fut Arctic SIC } \\
\text { and pd SST from coupled model }(2.1) \\
\text { rather than observations }\end{array}$ & & 3 & 2000 & 1 & 100 \\
\hline
\end{tabular}

\begin{tabular}{|c|c|c|c|c|c|c|c|}
\hline \multicolumn{8}{|c|}{ 5. Atmosphere-only transient experiments } \\
\hline 5.1 & $\begin{array}{l}\text { amip- } \\
\text { climSST }\end{array}$ & $\begin{array}{l}\text { Repeat CMIP6 AMIP (1979-2014) } \\
\text { but with climatological monthly } \\
\text { mean SST }\end{array}$ & \multirow{2}{*}{$\begin{array}{l}\text { Use CMIP6 AMIP as } \\
\text { the control; investigate } \\
\text { transient response, indi- } \\
\text { vidual years and the } \\
\text { contributions of SST } \\
\text { and SIC to recent } \\
\text { climate changes }\end{array}$} & 3 & 1979 & 36 & 3 \\
\hline & amip-climSIC & $\begin{array}{l}\text { Repeat CMIP6 AMIP (1979-2014) } \\
\text { but with climatological monthly mean } \\
\text { SIC }\end{array}$ & & 3 & 1979 & 36 & 3 \\
\hline
\end{tabular}

6. Coupled ocean-atmosphere extended experiments

\begin{tabular}{|c|c|c|c|c|c|c|c|}
\hline 6.1 & pa-pdSIC-ext & $\begin{array}{l}\text { Coupled model extended simulation } \\
\text { constrained with pd sea ice }{ }^{4,6}\end{array}$ & \multirow{3}{*}{$\begin{array}{l}\text { Experiments to investi- } \\
\text { gate the decadal and } \\
\text { longer impacts of Arc- } \\
\text { tic and Antarctic sea } \\
\text { ice }\end{array}$} & 3 & 2000 & 100 & 1 \\
\hline 6.2 & $\begin{array}{l}\text { pa-fut } \\
\text { ArcSIC-ext }\end{array}$ & $\begin{array}{l}\text { Coupled model extended simulation } \\
\text { constrained with fut Arctic sea ice } 4,6\end{array}$ & & 3 & 2000 & 100 & 1 \\
\hline 6.3 & $\begin{array}{l}\text { pa-fut } \\
\text { AntSIC-ext }\end{array}$ & $\begin{array}{l}\text { Coupled model extended simulation } \\
\text { constrained with fut Antarctic sea } \\
\text { ice }^{4,6}\end{array}$ & & 3 & 2000 & 100 & 1 \\
\hline
\end{tabular}

Notes: radiative forcing to be set to present-day (year 2000) levels for all experiments, except AMIP (5.1 and 5.2), where the CMIP6 protocol should be used. ${ }^{1}$ All necessary SST and sea ice fields will be provided to participants (Appendix A). ${ }^{2}$ Time slice simulations to begin on 1 April and run for 14 months. The 1 -year long runs are required to isolate short-term atmospheric responses from longer-timescale ocean responses, which will be investigated separately (experiment 6 ). ${ }^{3}$ Past and future SIC and SST will be computed from the ensemble of CMIP5 projections (Appendix A). Sea ice thickness should be specified according to the CMIP6 AMIP protocol (Appendix B). ${ }^{4}$ Initial conditions for coupled model experiments to be taken from the year 2000 of coupled model historical simulations. ${ }^{5}$ Sea ice concentration to be nudged into coupled model with a relaxation timescale of 1 day. ${ }^{6}$ Present-day and future sea ice to be the same as used in experiments $1.1,1.6$ and 1.8 . It is recommended to constrain sea ice by nudging but with a weak relaxation timescale of 2 months. However, appropriately calibrated long-wave fluxes applied to the sea ice model (following Deser et al., 2015) may also be used.

See Appendix B for further discussion. 
each model before averaging across models, rather than calculating a ratio based on the multi-model-mean temperature changes (i.e. as a mean ratio, not a ratio of means).

The tier 1 experiments are atmosphere-only runs to minimise computational costs, and lower-tier experiments investigate additional aspects and provide further understanding of the physical processes. All experiments require a large ensemble to obtain robust results (Screen et al., 2014; Mori et al., 2014) and we encourage groups to submit more than the minimum requirement if they are able to. The experiments are listed in Table 1, and further technical details are given in Appendix B. Suggested combinations for diagnosing the roles of SST and sea ice in polar amplification, and the climate response to sea ice, are given in Table 2. The experiments are grouped into six sets as follows:

1. Atmosphere-only time slice. What are the relative roles of local sea ice and remote sea surface temperature changes in driving polar amplification, and how does the global climate system respond to changes in Arctic and Antarctic sea ice? This set contains all of the tier 1 experiments and provides a multi-model assessment of the primary scientific questions addressed by PAMIP. The difference between experiments 1.1 and 1.3 provides an estimate of the contribution of SST to the polar amplification between pre-industrial and present-day conditions. The contribution of Arctic (Antarctic) sea ice to polar amplification, as well as the atmospheric response to Arctic (Antarctic) sea ice changes between pre-industrial and present-day conditions, can be obtained by differencing experiments 1.1 and 1.5 (1.7). Note that the linearity of responses to SST and sea ice can be assessed by comparing with the total response diagnosed by differencing experiments 1.2 and 1.1. The contribution of Arctic (Antarctic) sea ice to future polar amplification, as well as the atmospheric response to Arctic (Antarctic) sea ice changes between presentday and future conditions, can be obtained by differencing experiments 1.1 and $1.6(1.8)$. Tier 2 experiment 1.4 provides an estimate of the contribution of SST to future polar amplification, and 1.2 provides an additional estimate of the contribution of SST to past polar amplification. Further estimates can be obtained by differencing future and pre-industrial periods. Sensitivity to the magnitude of the forcing can also be investigated since differences in SST and SIC between future and pre-industrial conditions are much larger than between present-day and future or pre-industrial conditions. Tier 3 experiments 1.9 and 1.10 enable the role of Arctic sea ice thickness changes to be assessed (see Appendix B for details of sea ice thickness specification).

2. Coupled ocean-atmosphere time slice. What role does ocean-atmosphere coupling play in the response to sea ice? Previous studies have shown that such coupling

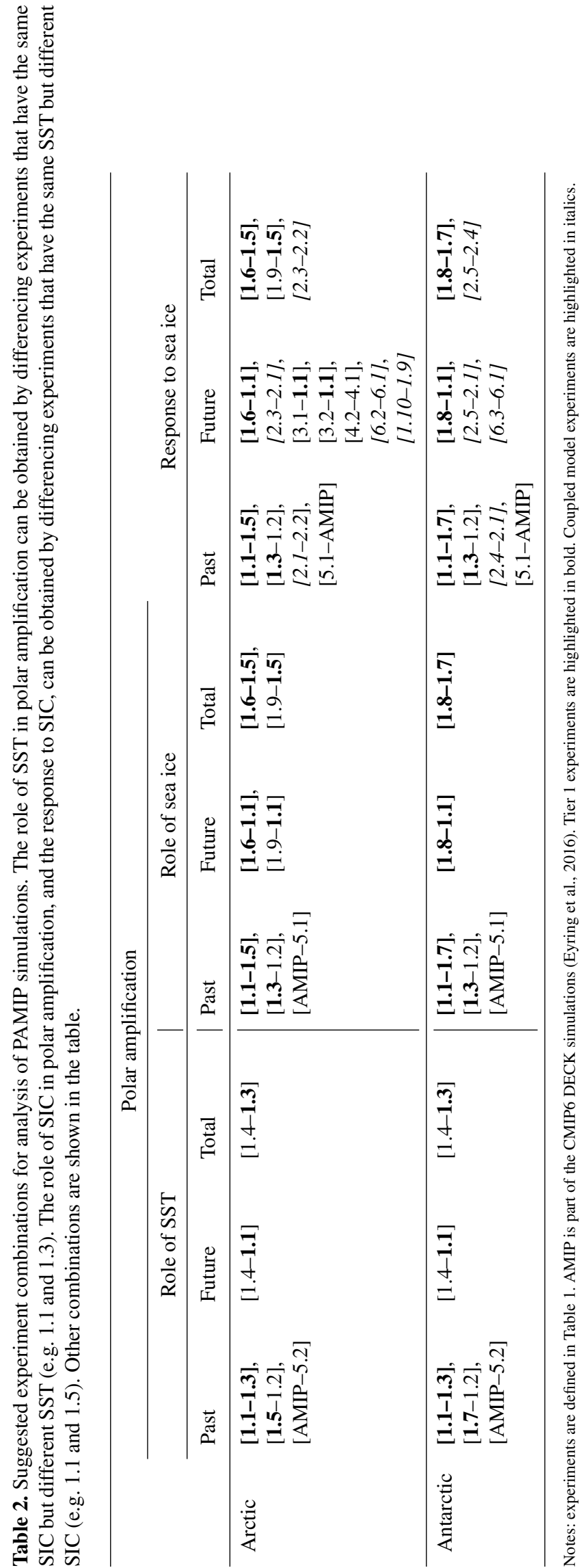

Geosci. Model Dev., 12, 1139-1164, 2019 


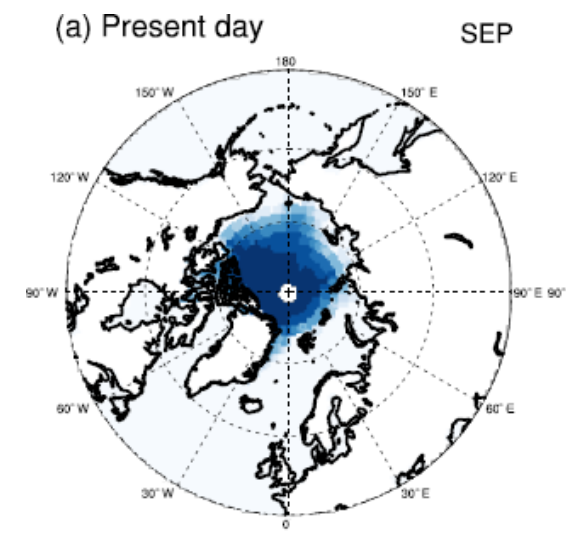

(b) Pre-ĩndustrial - present day

(c) Future - present day
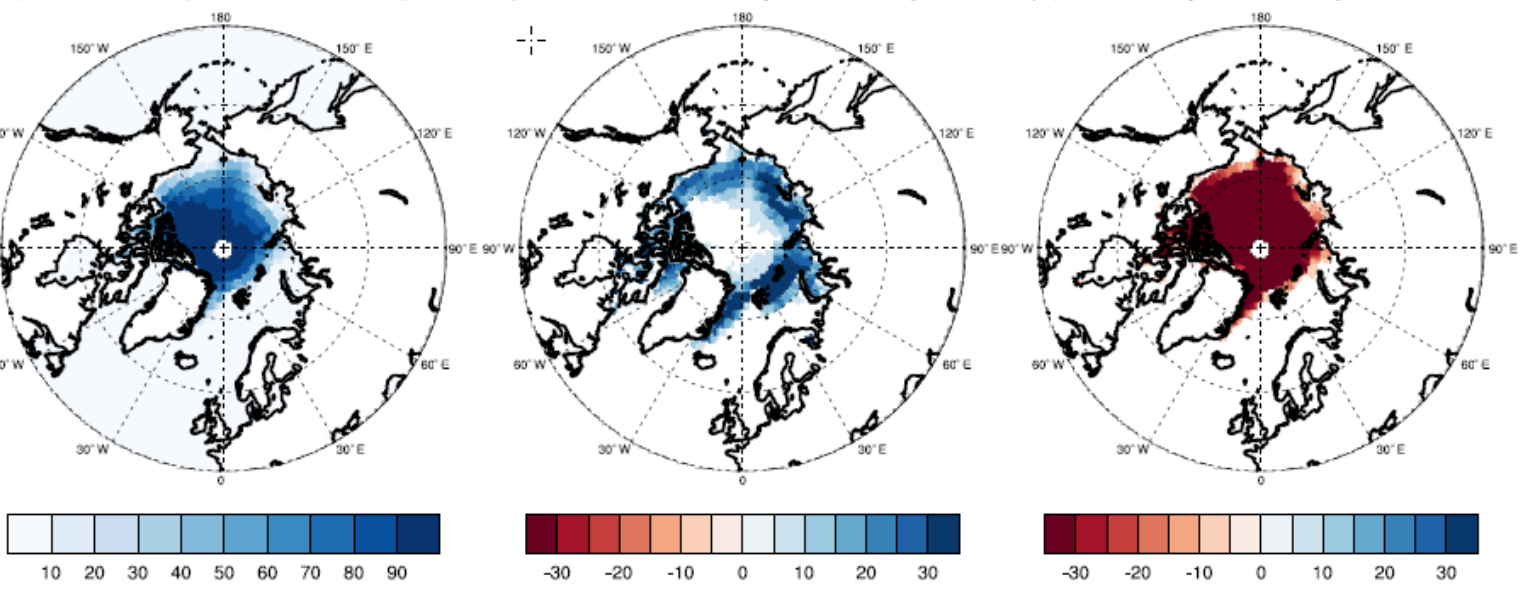

(d) Present day MAR

(e) Pre-industrial - present day

(f) Future - present day
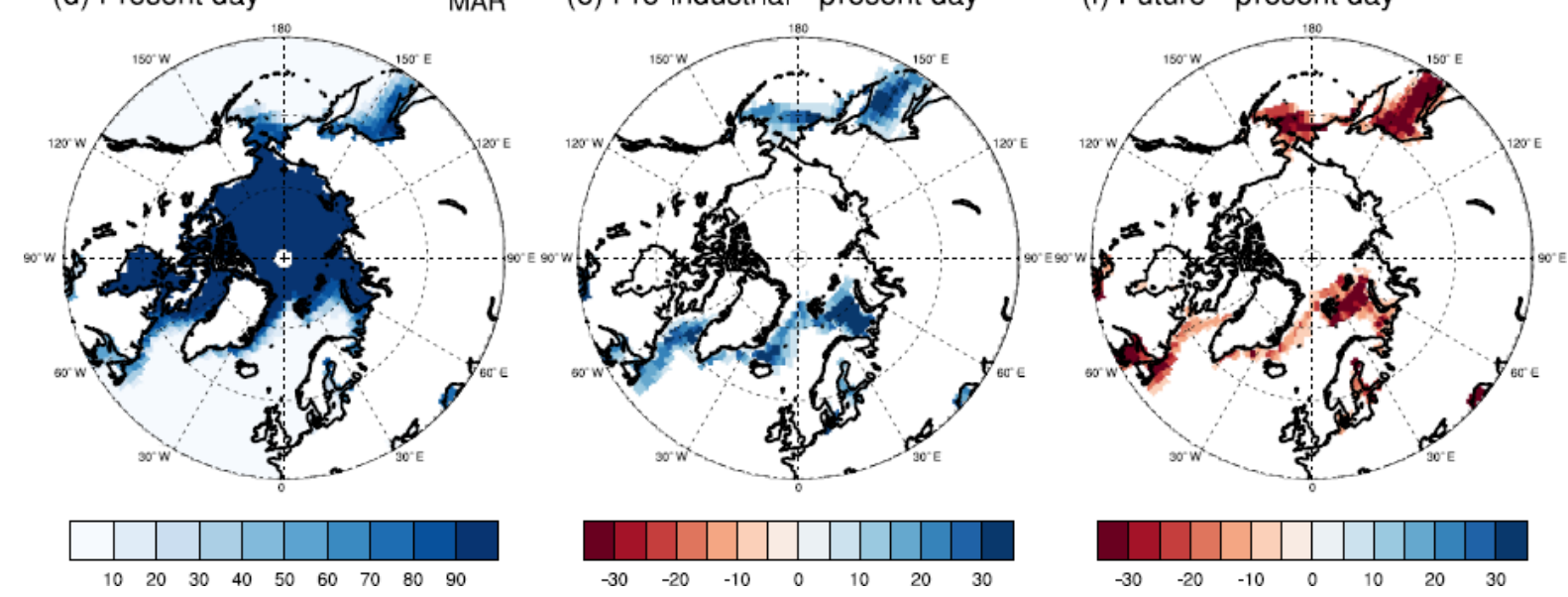

Figure 5. Arctic sea ice forcing fields. Present-day Arctic sea ice concentration for (a) September and (d) March. Differences from presentday fields are shown for $(\mathbf{b}, \mathbf{e})$ pre-industrial and $(\mathbf{c}, \mathbf{f})$ future conditions.

potentially amplifies the response and produces additional impacts in remote regions, including the tropics (Deser et al., 2015, 2016; Tomas et al., 2016; Smith et al., 2017; Oudar et al., 2017; Blackport and Kushner, 2017). Coupled model simulations are therefore needed to assess the full response to sea ice. These experiments impose the same SIC fields as used in the atmosphereonly experiments $(1.1,1.5$ to 1.8 ; see Appendix B for further details), allowing an assessment of the role of coupling. However, it is important to note that the background states are likely to be different between the coupled model and atmosphere-only simulations, and experiment set 4 is needed to isolate the effects of coupling (Smith et al., 2017). Experiment set 2 focusses on the short-term effects of the ocean, but the full effects will likely take longer to become established and are investigated in experiment set 6 .
3. Atmosphere-only time slice experiments to investigate regional forcing. How and why does the atmospheric response to Arctic sea ice depend on the regional pattern of sea ice forcing? Previous studies have found that the atmospheric response is potentially very sensitive to the pattern of sea ice forcing (Sun et al., 2015; Screen, 2017). This sensitivity will be investigated by specifying SIC changes in two different regions: the Barents/Kara seas and the Sea of Okhotsk. These regions represent the Atlantic and Pacific sectors which potentially produce opposite responses in the stratosphere (Sun et al., 2015) and have been highlighted as important regions by several studies (e.g. Honda et al., 1996; Petoukhov and Semenov, 2010; Kim et al., 2014; Mori et al., 2014; Kug et al., 2015; Screen, 2013, 2017).

4. Atmosphere-only time slice experiments to investigate the role of the model background state. How and why does the atmospheric response to Arctic sea ice depend 


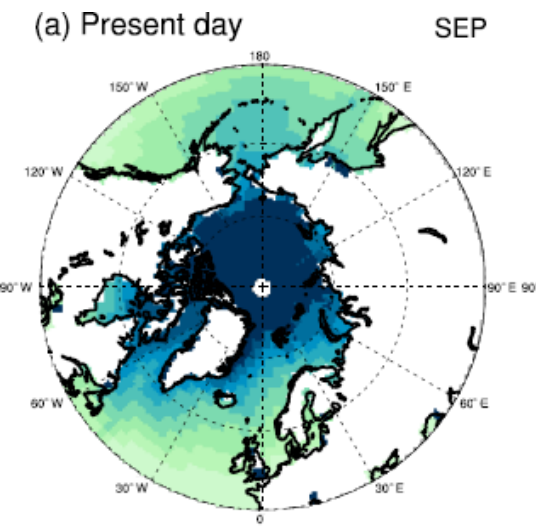

(b) Pre-industrial - present day

(c) Future - present day
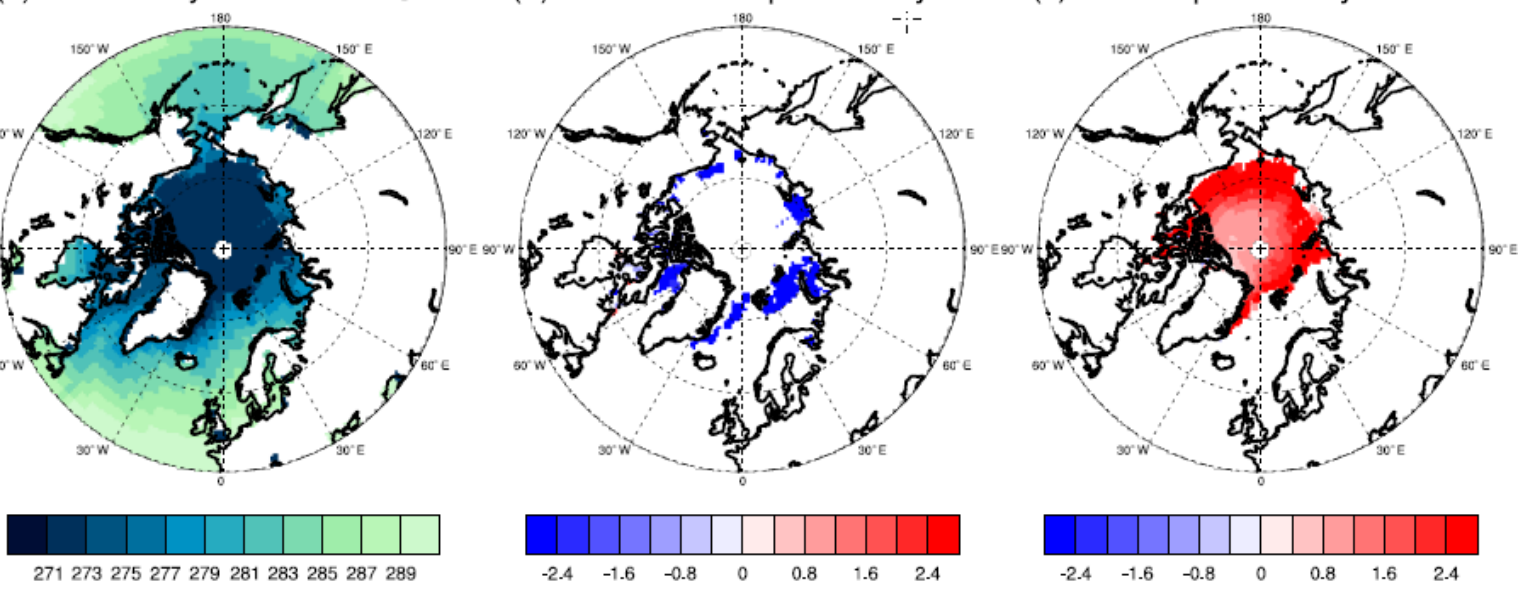

(d) Present day MAR

(e) Pre-industrial - present day
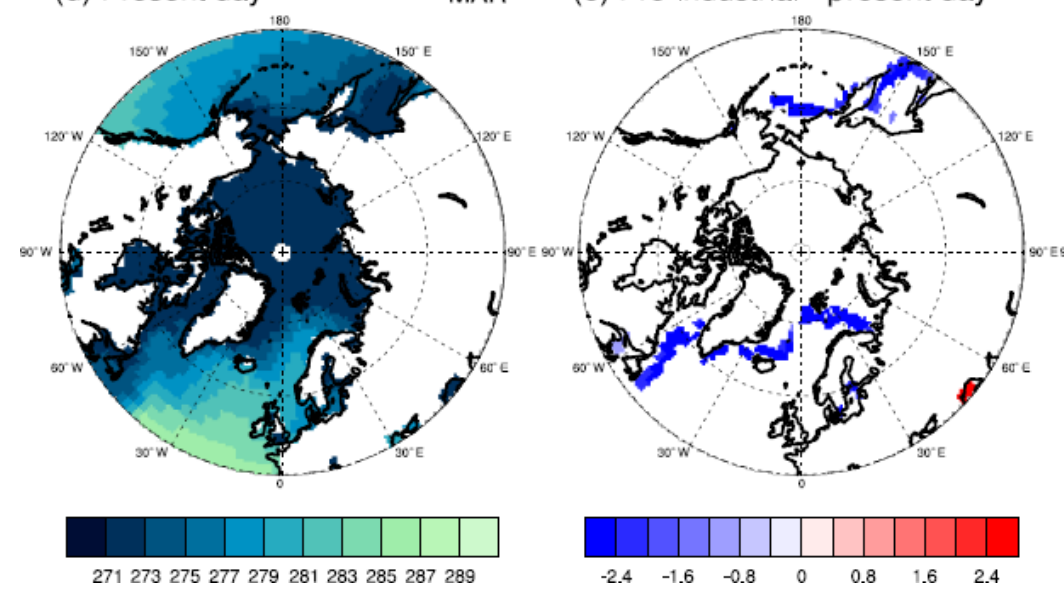

(f) Future - present day

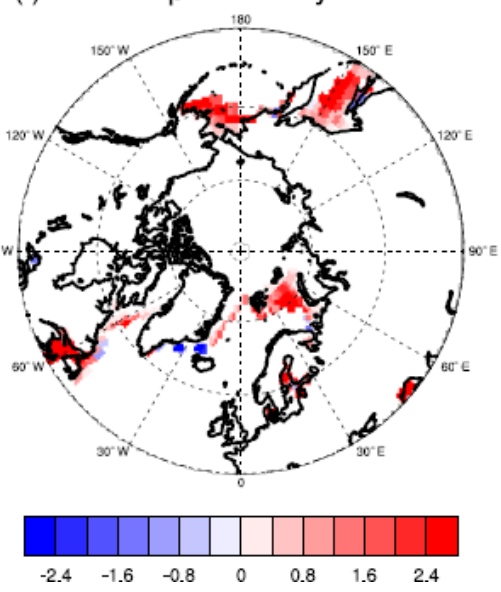

Figure 6. Arctic SST forcing fields. Present-day Arctic SST for (a) September and (d) March. Differences from present-day fields are shown for $(\mathbf{b}, \mathbf{e})$ pre-industrial and $(\mathbf{c}, \mathbf{f})$ future conditions.

on the model background state? The atmospheric response to sea ice is potentially sensitive to the model background state (Balmaseda et al., 2010; Smith et al., 2017). This is investigated in experiment set 4 by repeating the atmosphere-only experiments (1.1 and 1.6) but specifying the climatological average SST obtained from the coupled model experiment (2.1) for the same model (as detailed in Appendix B), thereby imposing the coupled model biases. Analysis of the physical processes giving rise to sensitivity to background state could lead to an "emergent constraint" to determine the real-world situation (Smith et al., 2017), as discussed further below. Furthermore, experiment sets 1, 2 and 4 together enable the role of coupling to be isolated, assuming the influences of coupling and background state are linear.

5. Atmosphere-only transient experiments. What have been the relative roles of SST and SIC in observed polar amplification over the recent period since 1979? These experiments are atmosphere-only simulations of the period starting in 1979. The control is a CMIP6 DECK experiment (Eyring et al., 2016) driven by the observed time series of monthly mean SST and SIC; if necessary, the ensemble size should be increased to be the same as the PAMIP experiments. Replacing the monthly mean time series with the climatological averages for SST and SIC separately enables the impacts of transient SST and SIC to be diagnosed. Individual years of interest, and the transient response to sea ice loss, may also be investigated. Note that to obtain robust results from a single model it may be necessary to provide 30 or more ensemble members (Sun et al., 2016).

6. Coupled ocean-atmosphere extended experiments. How does the global climate response to sea ice evolve on decadal and longer timescales? Previous studies suggest that the response to Arctic sea ice could be mod- 


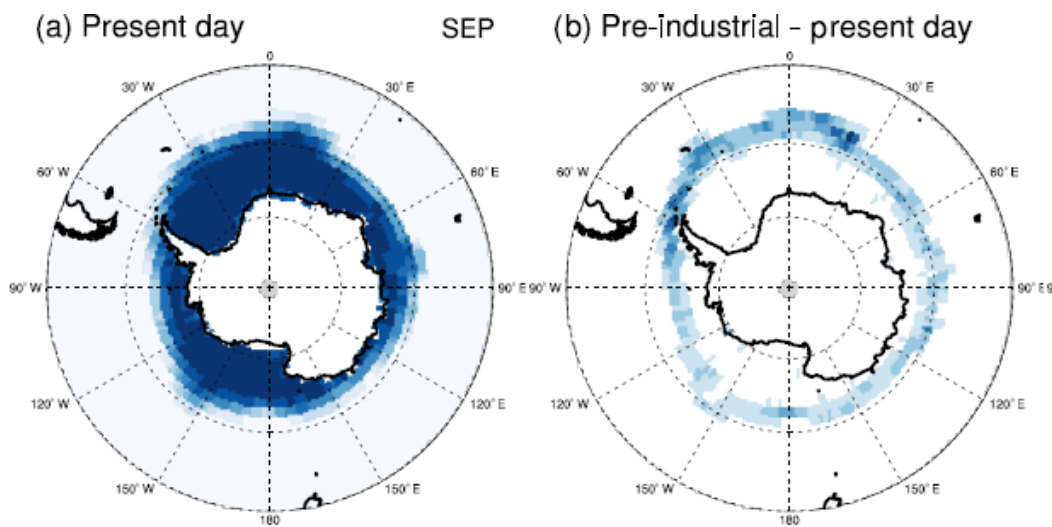

(c) Future - present day
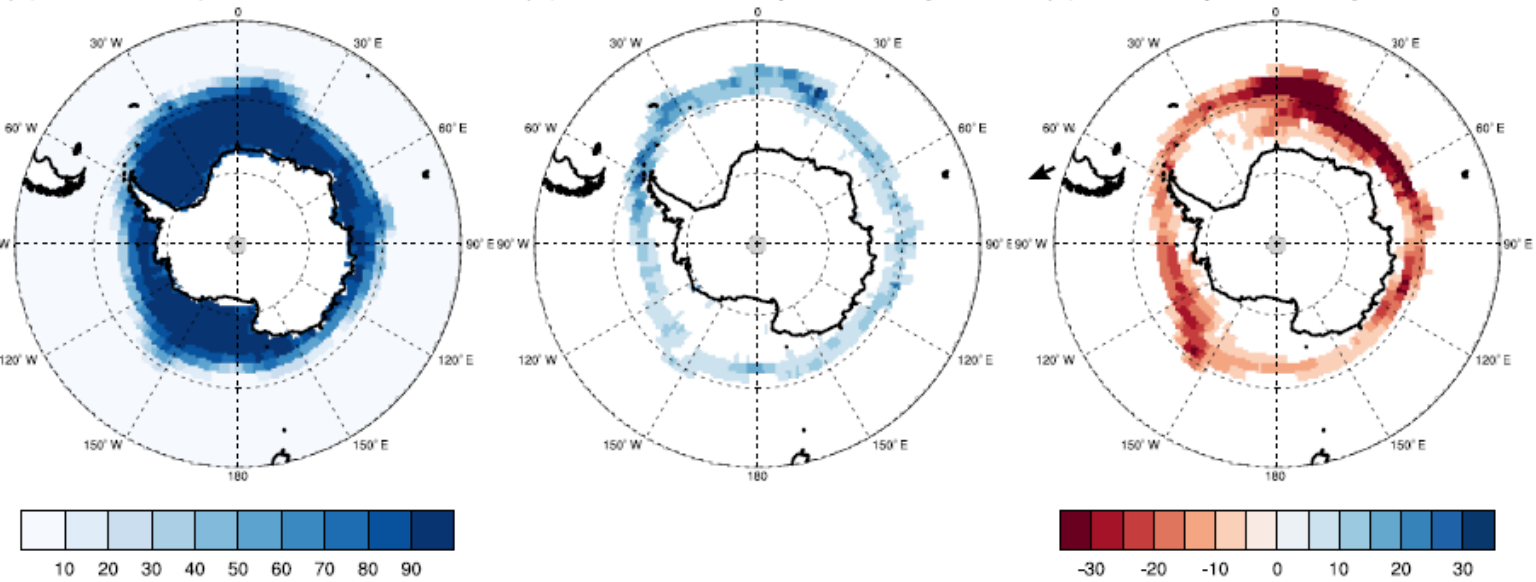

(d) Present day MAR

(e) Pre-industrial - present day
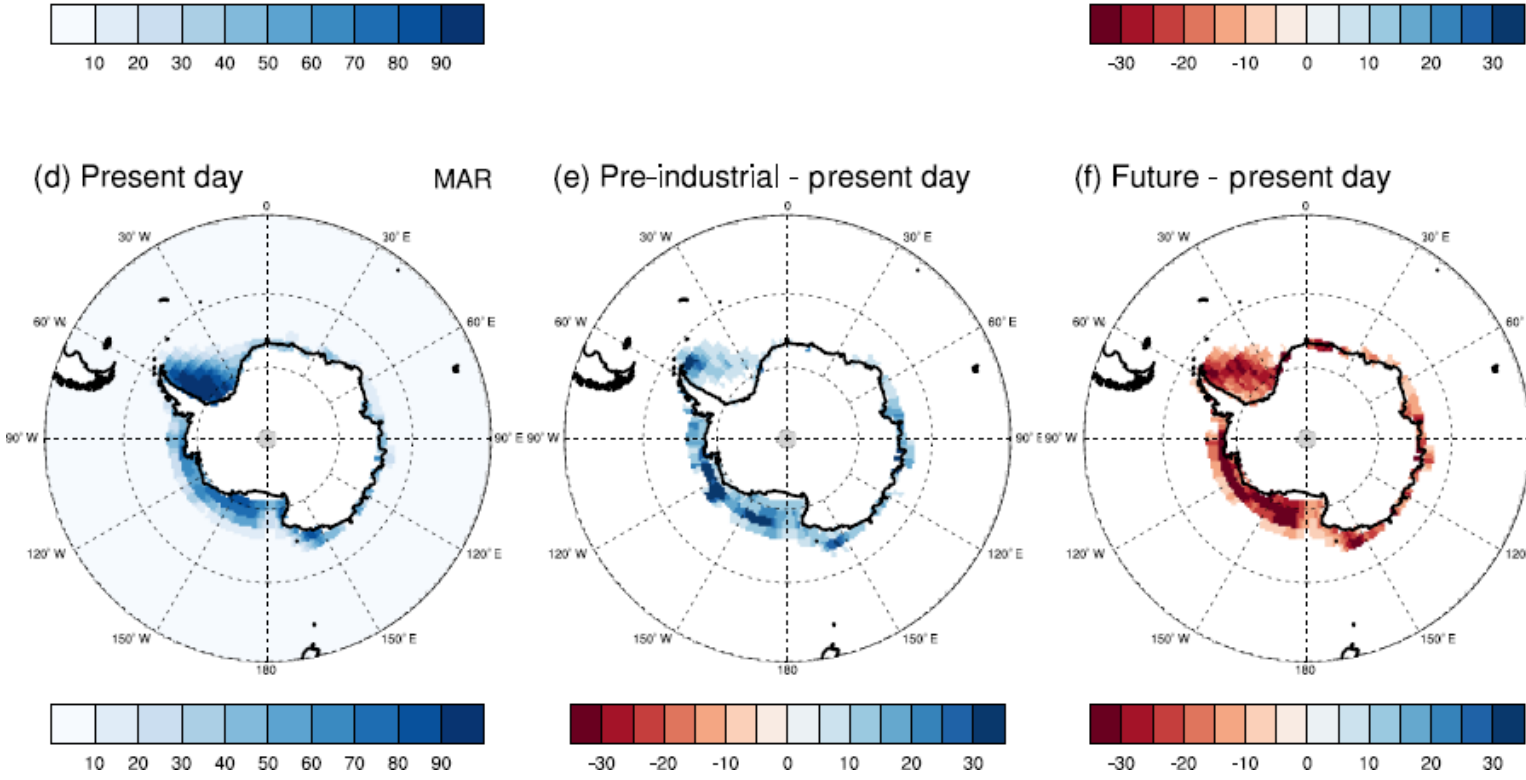

(f) Future - present day

Figure 7. Antarctic sea ice forcing fields. Present-day Antarctic sea ice concentration for (a) September and (d) March. Differences from present-day fields are shown for $(\mathbf{b}, \mathbf{e})$ pre-industrial and $(\mathbf{c}, \mathbf{f})$ future conditions.

ulated by decadal and longer-timescales changes in the ocean (Tomas et al., 2016; Sévellec et al., 2017). This may alter the pattern of tropical SST response which in turn may modulate changes in the Atlantic and Pacific ITCZs found in some studies (Chiang and Bitz, 2005; Smith et al., 2017). Although experiment set 2 uses coupled models, the simulations are too short to capture changes in ocean circulation which occur on decadal and longer timescales. Hence, experiment set 6 will investigate the decadal-to-centennial timescale response to sea ice using coupled model simulations in which sea ice is constrained to desired values (see Appendix B for further details). Groups that are able to are encouraged to extend simulations up to 200 years to ensure that the longer-timescale impacts are captured.

A key goal of PAMIP is to determine the real-world situation. Although the experiments are coordinated we anticipate a large spread in the model simulations. However, if the physical processes responsible for differences between models can be understood, then the model spread can be exploited to obtain an estimate of the real-world situation using the concept of "emergent constraints" (Hall and Qu, 2006; Collins et al., 2012; Bracegirdle and Stephenson, 2013). For example, results using a single model but with different background states suggest that differences in the simulated Atlantic jet response to Arctic sea ice loss might be explained by the climatological planetary wave refractive index, observations of which suggest a moderate weakening of the jet in reality (Fig. 9, Smith et al., 2017). The multi-model PAMIP simulations will be used to test the robustness of this relationship and to identify other constraints to identify the real world's response to sea ice and the factors contributing to polar amplification. 
(a) Present day

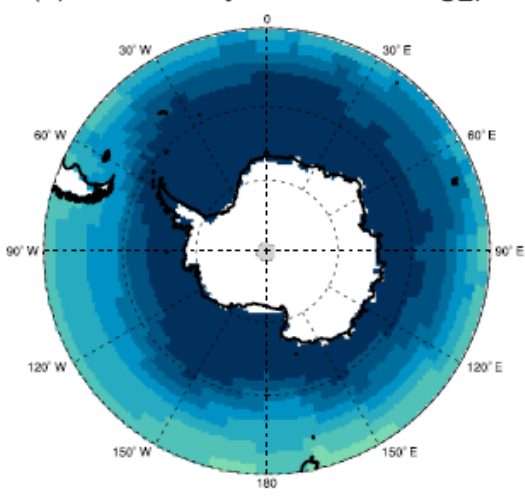

271273275277279281283285287289 (b) Pre-industrial - present day
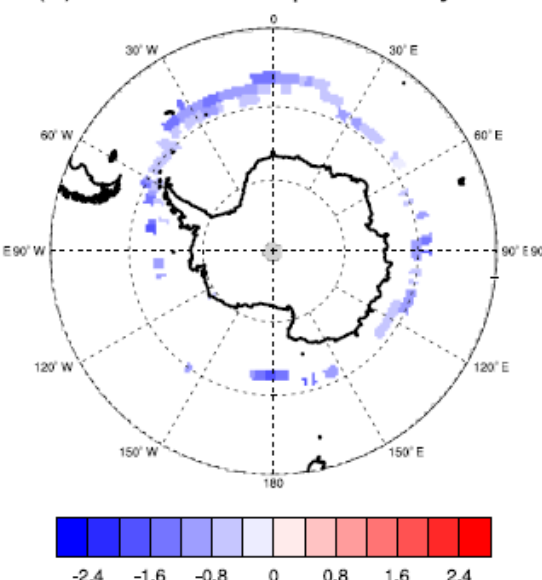

$\begin{array}{lllllll}-2.4 & -1.6 & -0.8 & 0 & 0.8 & 1.6 & 2.4\end{array}$ (c) Future - present day
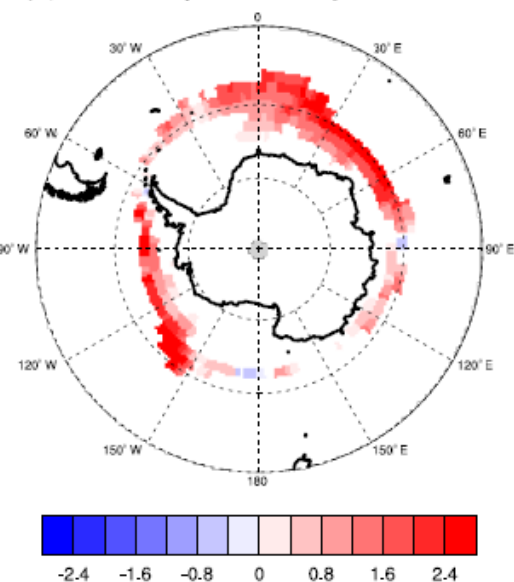

(d) Present day

MAR

(e) Pre-industrial - present day

(f) Future - present day
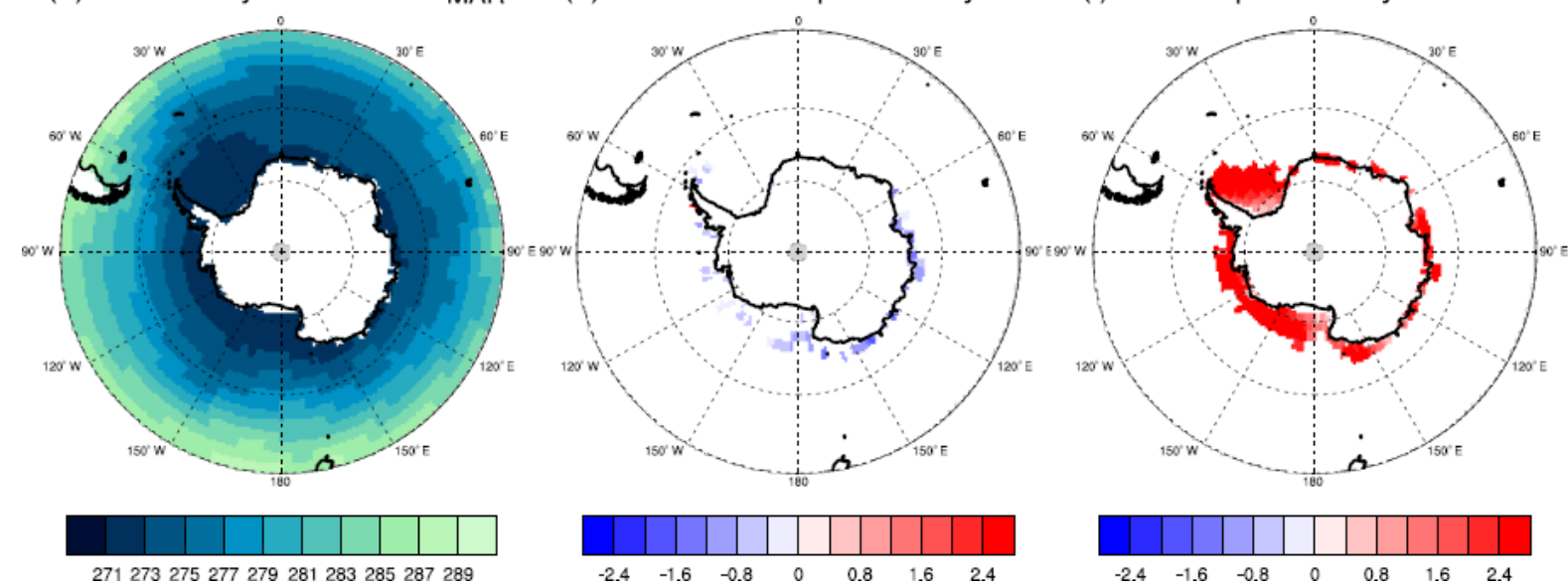

Figure 8. Antarctic SST forcing fields. Present-day Antarctic SST for (a) September and (d) March. Differences from present-day fields are shown for (b, e) pre-industrial and $(\mathbf{c}, \mathbf{f})$ future conditions.

\section{Data request}

The final definitive data request for PAMIP is documented in the CMIP6 data request, available at https://www. earthsystemcog.org/projects/wip/CMIP6DataRequest (last access: 20 March 2019). The requested diagnostics are the same for all PAMIP experiments and will enable climate change and variability to be characterised and the underlying physical processes to be investigated. The PAMIP data request is the same as for the Decadal Climate Prediction Project (DCPP) (see Appendix D in Boer et al., 2016) with the addition of wave activity diagnostics. Many studies have suggested that wave activity plays a key role in the atmospheric response to sea ice. However, the physical mechanism is poorly understood, with some studies highlighting increased wave activity (Jaiser et al., 2013; Kim et al., 2014; Peings and Magnusdottir, 2014; Feldstein and Lee, 2014; García-Serrano et al., 2015; Sun et al., 2015;
Nakamura et al., 2015; Overland et al., 2016) and others showing reduced wave activity (Seierstad and Bader, 2009; Wu and Smith, 2016; Smith et al., 2017) in response to reduced Arctic sea ice. Hence, important additions to the DCPP data request are monthly mean wave activity fluxes on pressure levels (Table 3) for diagnosing atmospheric zonal momentum transport as documented in the Dynamics and Variability MIP (DynVarMIP; see Gerber and Manzini, 2016, for details on how to compute these variables). We stress that the data request is not intended to exclude other variables and participants are encouraged to retain variables requested by other MIPs if possible.

\section{Interactions with DECK and other MIPs}

The CMIP6 DECK experiments (Eyring et al., 2016) characterise the sensitivity to external forcings and the levels of internal variability in each model and therefore provide valu- 
Table 3. Requested variables for diagnosing atmospheric zonal momentum transport. Zonal mean variables (2-D, grid: YZT) on the plev39 grid (or a subset of plev39 for models which do contain all of the requested levels).

\begin{tabular}{|c|c|}
\hline Name & Long name (unit) \\
\hline ua & Eastward wind $\left(\mathrm{m} \mathrm{s}^{-1}\right)$ \\
\hline epfy & $\begin{array}{l}\text { Northward component of the Eliassen-Palm flux } \\
\left(\mathrm{m}^{3} \mathrm{~s}^{-2}\right)\end{array}$ \\
\hline epfz & $\begin{array}{l}\text { Upward component of the Eliassen-Palm flux } \\
\left(\mathrm{m}^{3} \mathrm{~s}^{-2}\right)\end{array}$ \\
\hline vtem & $\begin{array}{l}\text { Transformed Eulerian mean northward wind } \\
\left(\mathrm{m} \mathrm{s}^{-1}\right)\end{array}$ \\
\hline wtem & $\begin{array}{l}\text { Transformed Eulerian mean upward wind } \\
\left(\mathrm{m} \mathrm{s}^{-1}\right)\end{array}$ \\
\hline utendepfd & $\begin{array}{l}\text { Tendency of eastward wind due to Eliassen-Palm } \\
\text { flux divergence }\left(\mathrm{m} \mathrm{s}^{-2}\right)\end{array}$ \\
\hline
\end{tabular}

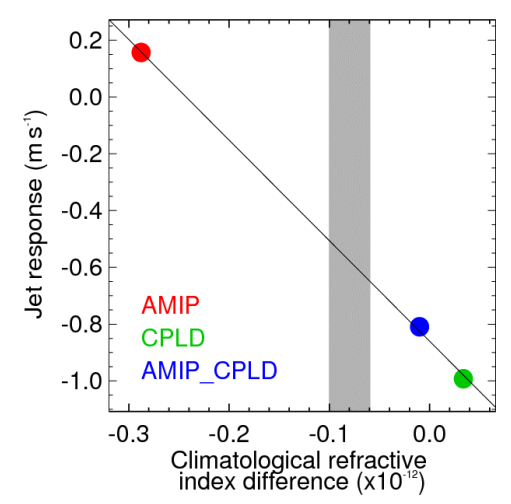

Figure 9. Potential emergent constraint on atmospheric response to Arctic sea ice. Dependence of Atlantic jet response to reduced Arctic sea ice on the background climatological refractive index difference between midlatitudes $\left(25-35^{\circ} \mathrm{N}\right)$ and high latitudes $(60$ $80^{\circ} \mathrm{N}$ ) at $200 \mathrm{hPa}$. Grey shading shows the observed range from the ERA-Interim and NCEP II reanalyses. The Atlantic jet response is defined as the difference in zonal mean zonal wind at $200 \mathrm{hPa}$ over the region $50-60^{\circ} \mathrm{N}, 60-0^{\circ} \mathrm{W}$ between model experiments with reduced and climatological Arctic sea ice. Experiments were performed with the same model but with three different configurations: atmosphere only (AMIP); fully coupled (CPLD); and atmosphere only but with SST biases from the coupled model (AMIP_CPLD). An "emergent constraint" is obtained where the observed refractive index difference (grey shading) intersects the simulated response (black line), suggesting a modest weakening of the Atlantic jet in response to reduced Arctic sea ice. Source: Smith et al. (2017).

able information for interpreting the PAMIP experiments. The DECK AMIP experiment forms the basis for PAMIP experiment set 5 , and the coupled model historical simulation is required to provide starting conditions for experiment sets 2 and 6.

PAMIP will compliment other CMIP6 MIPs, several of which will also provide valuable information on the causes and consequences of polar amplification. In particular, the magnitudes of polar amplification simulated by different models in response to future and past radiative forcings will be assessed from Scenario MIP (O'Neill et al., 2016) and Paleoclimate MIP (Kageyama et al., 2018). The roles of external factors including solar variability, volcanic eruptions, ozone, anthropogenic aerosols and greenhouse gases in driving polar amplification will be studied using experiments proposed in Detection and Attribution MIP (Gillett et al., 2016), Geoengineering MIP (Kravitz et al., 2015), Aerosols and Chemistry MIP (Collins et al., 2017) and Volcanic Forcings MIP (Zanchettin et al., 2016); and the roles of AMV and PDV will be studied using experiments proposed by the DCPP (Boer et al., 2016) and Global Monsoons MIP (Zhou et al., 2016).

The impacts of polar amplification on polar ice sheets and carbon uptake will be investigated by the Ice Sheet MIP (Nowicki et al., 2016) and the Coupled Climate-Carbon Cycle MIP (Jones et al., 2016a), respectively. Some information on the impacts of reduced sea ice on the atmospheric circulation can be obtained from experiments proposed by Cloud Feedback MIP (CFMIP; Webb et al., 2017) in which an atmosphere model is run twice, forced by the same SSTs but different sea ice concentration fields. However, the CFMIP experiments are not specifically designed to investigate the response to sea ice, and interpreting them is complicated by the fact that the forcing fields will be different for each model.

Improved understanding of the causes and consequences of polar amplification gained through PAMIP and other MIPs will help to interpret decadal predictability diagnosed in DCPP and will reduce the uncertainties in future projections of climate change in polar regions and associated climate impacts, thereby contributing to the Vulnerability, Impacts, Adaptation, and Climate Services (VIACS) Advisory Board (Ruane et al., 2016).

\section{Summary}

Polar amplification - the phenomenon where external radiative forcing produces a larger change in surface temperature at high latitudes than the global average - is robustly simulated by climate models in response to increasing greenhouse gases. Polar amplification is projected to occur at both poles but to be delayed in the Antarctic relative to the Arctic due to strong heat uptake in the Southern Ocean. Arctic amplification appears to be already underway, with recent Arctic warming trends approximately twice as large as the global average and reductions in summer sea ice extent of more than $10 \%$ decade $^{-1}$. However, recent temperature trends in the Antarctic are non-uniform, with warming over the Antarctic Peninsula and cooling elsewhere, and sea ice extent has actually increased slightly over recent decades in contrast to most climate model simulations. 
Understanding the causes of polar amplification, and the drivers of recent trends in both the Arctic and Antarctic, represents a key scientific challenge and is important for reducing the uncertainties in projections of future climate change. Several different feedback mechanisms, operating at both high and low latitudes, have been identified but their relative roles are uncertain. Recent trends have also been influenced by external factors other than greenhouse gases, including aerosols, ozone and solar variations, and by changes in atmosphere and ocean circulations. A key uncertainty is the relative role of local processes that directly affect the surface energy budget and remote processes that affect the poleward atmospheric heat transport. This balance helps to highlight the main feedbacks and processes that drive polar amplification, and can easily be assessed in numerical model experiments by separately imposing changes in sea ice concentration and remote SSTs. Such experiments have been performed in recent studies (Screen et al., 2012; Perlwitz et al., 2015), but additional models are needed to obtain robust results. PAMIP will therefore provide a robust multi-model assessment of the roles of local sea ice and remote SSTs in driving polar amplification. The tier 1 experiments focus on the changes between pre-industrial and present-day conditions, while lower-tier experiments enable recent decades and future conditions to be investigated.

There is mounting evidence that polar amplification will affect the atmosphere and ocean circulation, with potentially important climate impacts in both the midlatitudes and the tropics. In particular, polar amplification will reduce the Equator-to-pole surface temperature gradient which might be expected to weaken midlatitude westerly winds, promoting cold winters in parts of Europe, North America and Asia. Furthermore, enhanced warming of the Northern Hemisphere relative to the Southern Hemisphere might be expected to shift tropical rainfall northwards and potentially influence tropical storm activity. However, despite many studies and intensive scientific debate, there is a lack of consensus on the impacts of reduced sea ice cover in climate model simulations, and the physical mechanisms are not fully understood. There are many potential reasons for disparity across models, including differences in the magnitude and pattern of sea ice changes considered, how the changes are imposed, the use of atmosphere-only or coupled models, and whether other forcings such as greenhouse gases are included. Hence, coordinated model experiments are needed and will be performed in PAMIP. The tier 1 experiments involve atmosphere-only models forced with different combinations of sea ice and/or sea surface temperatures representing present-day, pre-industrial and future conditions. The use of three periods allows the signals of interest to be diagnosed in multiple ways. Lower-tier experiments are proposed to investigate additional aspects and provide further understanding of the physical processes. Specific questions addressed by these are as follows: what role does oceanatmosphere coupling play in the response to sea ice? How and why does the atmospheric response to Arctic sea ice depend on the pattern of sea ice forcing? How and why does the atmospheric response to Arctic sea ice depend on the model background state? What has been the response to sea ice over the recent period since 1979 ? How does the response to sea ice evolve on decadal and longer timescales?

A key goal of PAMIP is to determine the real-world situation. Although the experiments proposed here form a coordinated set, we anticipate large spread across models. However, this spread will be exploited by seeking "emergent constraints" in which the real-world situation is inferred from observations of a physical quantity that explains the model differences. For example, if differences in the midlatitude wind response to Arctic sea ice are caused by differences in the refraction of atmospheric waves across models, then observations of the refractive index may provide a constraint on the real-world response. In this way, improved process understanding gained through analysis of the unprecedented multimodel simulations generated by PAMIP will enable uncertainties in projections of future polar climate change and associated impacts to be reduced, and better climate models to be developed.

Code and data availability. The model output from PAMIP will be distributed through the Earth System Grid Federation (ESGF) with digital object identifiers (DOIs) assigned. The list of requested variables, including frequencies and priorities, is given in Appendix B and has been submitted as part of the "CMIP6 Data Request Compilation". As in CMIP5, the model output will be freely accessible through data portals after a simple registration process that is unique to all CMIP6 components. In order to document CMIP6's scientific impact and enable ongoing support of CMIP, users are requested to acknowledge CMIP6, the participating modelling groups and the ESGF centres (see details on the CMIP Panel website at http:// www.wcrp-climate.org/index.php/wgcm-cmip/about-cmip, last access: 20 March 2019). Further information about the infrastructure supporting CMIP6, the metadata describing the model output and the terms governing its use are provided by the WGCM Infrastructure Panel (WIP). Links to this information may be found on the CMIP6 website. Along with the data themselves, the provenance of the data will be recorded, and DOIs will be assigned to collections of output so that they can be appropriately cited. This information will be made readily available so that research results can be compared and the modelling groups providing the data can be credited.

The WIP is coordinating and encouraging the development of the infrastructure needed to archive and deliver the large amount of information generated by CMIP6. In order to run the experiments, datasets for SST and SIC forcing, along with natural and anthropogenic forcings, are required. SST and SIC forcing datasets for PAMIP are described in Appendix A and are available through the ESGF (https://esgf-node.llnl.gov/projects/input4mips/, last access: 20 March 2019) with version control and DOIs assigned. 


\section{Appendix A: SIC, SIT and SST forcing data}

Forcing fields for the PAMIP experiments are available from the input4MIPs data server (https://esgf-node.llnl.gov/ search/input4mips/, last access: 20 March 2019). Filenames of forcing data for each PAMIP experiment are provided in Table A1. The derivation of forcing data is described here.

Monthly mean fields of SIC, SIT and SST are required for the present-day, pre-industrial and future periods. For SST and SIC, present-day fields are obtained from the observations, using the 1979-2008 climatology from the Hadley Centre Sea Ice and Sea Surface Temperature data set (HadISST; Rayner et al., 2003). For SIT over the Arctic, present-day fields are obtained from the Pan-Arctic Ice Ocean Modeling and Assimilation System (PIOMAS; Zhang and Rothrock, 2003). Future and pre-industrial fields are obtained from the ensemble of 31 historical and RCP8.5 simulations from CMIP5 (see list of models in Table A2). However, models show a large spread in simulations of sea ice, so that a simple ensemble mean would produce an unrealistically diffuse ice edge. To obtain a more realistic ice edge, we use present-day observations to constraint the models, as follows:

- We define absolute global mean temperatures representing pre-industrial $\left(13.67^{\circ} \mathrm{C}\right)$, present-day $\left(14.24^{\circ} \mathrm{C}\right)$ and future $\left(2^{\circ}\right.$ warming, $\left.15.67^{\circ} \mathrm{C}\right)$ periods. The presentday global mean temperature corresponds to the 19792008 average from HadCRUT4 observations (Morice et al., 2012). The pre-industrial global mean temperature is obtained by removing from this present-day value an estimate of the global warming index (Haustein et al., 2017) for the period $1979-2008\left(0.57^{\circ} \mathrm{C}\right)$. The future global mean temperature is defined as $+2{ }^{\circ} \mathrm{C}$ from the pre-industrial period, i.e. $15.67^{\circ} \mathrm{C}$.

- For each model, find the periods when the 30-year mean global temperature equals the above values and compute the 30 -year averaged fields.

- At each grid point, use the observed present-day value to constrain the model simulations of future and preindustrial conditions. This is achieved by computing a linear regression across the models between future (or pre-industrial) and present-day values simulated by the model ensemble, and taking the required future (or preindustrial) estimate as the point where this regression relationship intersects the observed present-day value. We use quantile regression rather than least squares regression to reduce the impact of outliers and hence provide a sharper ice edge. This procedure is used to create past and future SIC/SST/SIT fields, with the quantile of the regression being chosen to increase the signal. For the future, the lower (upper) quartile regression is used for SIC/SIT (SST), in order to give more weight to models with less sea ice and warmer SST. Conversely, for the pre-industrial period, the upper (lower) quartile is used for SIC/SIT (SST), giving more weight to models with larger sea ice and cooler SST.

Some experiments, such as 1.6 , require SSTs to be specified in regions where the sea ice has been removed. We follow the methodology of Screen et al. (2013); i.e. we impose pre-industrial/future SST (derived from the quantile regression) in grid points where pre-industrial/future SIC deviates by more than $10 \%$ of its present-day value. Example SIC and SST fields are shown in Figs. 5-8.

In experiment 3, future sea ice changes are only imposed in the Barents/Kara seas and Sea of Okhotsk. Future SIC fields for these experiments were created by replacing present-day values with future values but only in the required regions, defined as $65-85^{\circ} \mathrm{N}, 10-110^{\circ} \mathrm{E}$ for the Barents/Kara seas and $40-63^{\circ} \mathrm{N}, 135-165^{\circ} \mathrm{E}$ for the Sea of Okhotsk.

For experiment 5, monthly mean SST and SIC climatologies were created from the CMIP6 AMIP data. For 5.1, SST is set to the transient values where sea ice substantially deviates (by more than 10\%) from climatology. For 5.2, SST is set to the transient values where sea ice is absent in the climatology but present in the transient fields, and $-1.8^{\circ} \mathrm{C}$ where sea ice is present in the climatology but absent in the transient fields.

For experiments 1.9 and 1.10, SIT in the Arctic is derived from PIOMAS. Since no SIT observations are available in the Antarctic, we use the median of present-day values simulated by the model ensemble. The same present-day SIT values are used in the Antarctic in the SIT forcing field of experiments 6.1 and 6.2. For experiment 6.3 (future Antarctic SIC/SIT), we use the lower quartile of future values simulated by the model ensemble. Where SIC is greater than $15 \%$, but SIT equals 0 , SIT is set to $15 \mathrm{~cm}$.

\section{Appendix B: Experiment details}

\section{AMIP II}

Before use, the forcing data (SST, SIC and SIT) should be processed following the standard AMIP II protocol (Taylor et al., 2000). This is to ensure that monthly means computed from the model (after interpolating to the required model time steps) agree with the monthly means in the forcing files.

\section{Radiative forcing}

Present-day radiative forcings, taken as the year 2000, should be used for all experiments, except set 5 , for which timevarying forcings for the period 1979 to 2014 should be specified in accordance with the AMIP protocol (Eyring et al., 2016). 
Table A1. Names of forcing files for each experiment. Files are available from the input4MIPs data server (https://esgf-node.llnl.gov/search/ input4mips/last access: 20 March 2019). Comments in square brackets are optional guidance for groups that are able to constrain sea ice thickness (sithick).

\begin{tabular}{|c|c|c|}
\hline No. & Experiment name & Names of forcing files \\
\hline 1.1 & pdSST-pdSIC & $\begin{array}{l}\text { tos_input4MIPs_SSTsAndSeaIce_PAMIP_UCI-present-1-0_gn_197901-200812-clim.nc } \\
\text { siconc_input4MIPs_SSTsAndSeaIce_PAMIP_UCI-present-1-0_gn_197901-200812-clim.nc }\end{array}$ \\
\hline 1.2 & piSST-piSIC & $\begin{array}{l}\text { tos_input4MIPs_SSTsAndSeaIce_PAMIP_UCI-preindustrial-1-0_gn_187001-188012-clim.nc } \\
\text { siconc_input4MIPs_SSTsAndSeaIce_PAMIP_UCI-preindustrial-1-0_gn_187001-188012-clim.nc }\end{array}$ \\
\hline 1.3 & piSST-pdSIC & $\begin{array}{l}\text { tos_input4MIPs_SSTsAndSeaIce_PAMIP_UCI-pi-prArctic-prAntarctic-1-0_gn_187001-188012-clim.nc } \\
\text { siconc_input4MIPs_SSTsAndSeaIce_PAMIP_UCI-present-1-0_gn_197901-200812-clim.nc }\end{array}$ \\
\hline 1.4 & futSST-pdSIC & $\begin{array}{l}\text { tos_input4MIPs_SSTsAndSeaIce_PAMIP_UCI-fu-prArctic-prAntarctic-1-0_gn_clim.nc } \\
\text { siconc_input4MIPs_SSTsAndSeaIce_PAMIP_UCI-present-1-0_gn_197901-200812-clim.nc }\end{array}$ \\
\hline 1.5 & pdSST-piArcSIC & $\begin{array}{l}\text { tos_input4MIPs_SSTsAndSeaIce_PAMIP_UCI-piArctic-1-0_gn_187001-188012-clim.nc } \\
\text { siconc_input4MIPs_SSTsAndSeaIce_PAMIP_UCI-piArctic-1-0_gn_187001-188012-clim.nc }\end{array}$ \\
\hline 1.6 & pdSST-futArcSIC & $\begin{array}{l}\text { tos_input4MIPs_SSTsAndSeaIce_PAMIP_UCI-fut2CArctic-1-0_gn_clim.nc } \\
\text { siconc_input4MIPs_SSTsAndSeaIce_PAMIP_UCI-fut2CArctic-1-0_gn_clim.nc }\end{array}$ \\
\hline 1.7 & pdSST-piAntSIC & $\begin{array}{l}\text { tos_input4MIPs_SSTsAndSeaIce_PAMIP_UCI-piAntarctic-1-0_gn_187001-188012-clim.nc } \\
\text { siconc_input4MIPs_SSTsAndSeaIce_PAMIP_UCI-piAntarctic-1-0_gn_187001-188012-clim.nc }\end{array}$ \\
\hline 1.8 & pdSST-futAntSIC & $\begin{array}{l}\text { tos_input4MIPs_SSTsAndSeaIce_PAMIP_UCI-fut2CAntarctic-1-0_gn_clim.nc } \\
\text { siconc_input4MIPs_SSTsAndSeaIce_PAMIP_UCI-fut2CAntarctic-1-0_gn_clim.nc }\end{array}$ \\
\hline 1.9 & pdSST-pdSICSIT & $\begin{array}{l}\text { tos_input4MIPs_SSTsAndSeaIce_PAMIP_UCI-present-1-0_gn_197901-200812-clim.nc } \\
\text { siconc_input4MIPs_SSTsAndSeaIce_PAMIP_UCI-present-1-0_gn_197901-200812-clim.nc } \\
\text { sithick_input4MIPs_SSTsAndSeaIce_PAMIP_UCI-present-2mAntarctic-1-0_gn_197901-200812-clim.nc }\end{array}$ \\
\hline 1.10 & $\begin{array}{l}\text { pdSST- } \\
\text { futArcSICSIT }\end{array}$ & $\begin{array}{l}\text { tos_input4MIPs_SSTsAndSeaIce_PAMIP_UCI-fut2CArctic-1-0_gn_clim.nc } \\
\text { siconc_input4MIPs_SSTsAndSeaIce_PAMIP_UCI-fut2CArctic-1-0_gn_clim.nc } \\
\text { sithick_input4MIPs_SSTsAndSeaIce_PAMIP_UCI-fut2CArctic-2mAntarctic-1-0_gn_clim.nc }\end{array}$ \\
\hline 2.1 & pa-pdSIC & $\begin{array}{l}\text { siconc_input4MIPs_SSTsAndSeaIce_PAMIP_UCI-present-1-0_gn_197901-200812-clim.nc } \\
\text { (sithick as used in experiment 1.1) }\end{array}$ \\
\hline 2.2 & pa-piArcSIC & $\begin{array}{l}\text { siconc_input4MIPs_SSTsAndSeaIce_PAMIP_UCI-piArctic-1-0_gn_187001-188012-clim.nc } \\
\text { (sithick as used in experiment 1.5) }\end{array}$ \\
\hline 2.3 & pa-futArcSIC & $\begin{array}{l}\text { siconc_input4MIPs_SSTsAndSeaIce_PAMIP_UCI-fut2CArctic-1-0_gn_clim.nc (sithick as used in experi- } \\
\text { ment 1.6) }\end{array}$ \\
\hline 2.4 & pa-piAntSIC & $\begin{array}{l}\text { siconc_input4MIPs_SSTsAndSeaIce_PAMIP_UCI-piAntarctic-1-0_gn_187001-188012-clim.nc } \\
\text { (sithick as used in experiment 1.7) }\end{array}$ \\
\hline 2.5 & pa-futAntSIC & $\begin{array}{l}\text { siconc_input4MIPs_SSTsAndSeaIce_PAMIP_UCI-fut2CAntarctic-1-0_gn_clim.nc } \\
\text { (sithick as used in experiment 1.8) }\end{array}$ \\
\hline 3.1 & $\begin{array}{l}\text { pdSST- } \\
\text { futOkhotskSIC }\end{array}$ & $\begin{array}{l}\text { tos_input4MIPs_SSTsAndSeaIce_PAMIP_UCI-fut2COkhotsk-1-0_gn_clim.nc } \\
\text { siconc_input4MIPs_SSTsAndSeaIce_PAMIP_UCI-fut2COkhotsk-1-0_gn_clim.nc }\end{array}$ \\
\hline 3.2 & $\begin{array}{l}\text { pdSST- } \\
\text { futBKSeasSIC }\end{array}$ & $\begin{array}{l}\text { tos_input4MIPs_SSTsAndSeaIce_PAMIP_UCI-fut2CBKSeas-1-0_gn_clim.nc } \\
\text { siconc_input4MIPs_SSTsAndSeaIce_PAMIP_UCI-fut2CBKSeas-1-0_gn_clim.nc }\end{array}$ \\
\hline 4.1 & modelSST-pdSIC & $\begin{array}{l}\text { tos to be created from experiment } 2.1 \text { as described in Appendix B } \\
\text { siconc_input4MIPs_SSTsAndSeaIce_PAMIP_UCI-present-1-0_gn_197901-200812-clim.nc }\end{array}$ \\
\hline 4.2 & $\begin{array}{l}\text { modelSST- } \\
\text { futArcSIC }\end{array}$ & $\begin{array}{l}\text { tos to be created from experiment } 2.1 \text { as described in Appendix B } \\
\text { siconc_input4MIPs_SSTsAndSeaIce_PAMIP_UCI-fut2CArctic-1-0_gn_clim.nc }\end{array}$ \\
\hline
\end{tabular}


Table A1. Continued.

\begin{tabular}{lll}
\hline No. & Experiment name & Names of forcing files \\
\hline 5.1 & amip-climSST & $\begin{array}{l}\text { tos_input4MIPs_SSTsAndSeaIce_PAMIP_UCI-present-197901-201412-Arctic-Antarctic-1- } \\
\text { 0_gn_197901-201412-clim.nc } \\
\text { siconc_input4MIPs_SSTsAndSeaIce_PAMIP_UCI-present-1-0_gn_197901-201412.nc }\end{array}$ \\
\hline 5.2 & amip-climSIC & $\begin{array}{l}\text { tos_input4MIPs_SSTsAndSeaIce_PAMIP_UCI-present-197901-201412-clim-Arctic-Antarctic-1- } \\
\text { 0_gn_197901-201412.nc } \\
\end{array}$ \\
& siconc_input4MIPs_SSTsAndSeaIce_PAMIP_UCI-present-1-0_gn_197901-201412-clim.nc \\
\hline 6.1 & pa-pdSIC-ext & $\begin{array}{l}\text { siconc_input4MIPs_SSTsAndSeaIce_PAMIP_UCI-present-1-0_gn_197901-200812-clim.nc } \\
\text { (sithick_input4MIPs_SSTsAndSeaIce_PAMIP_UCI-present-1-0_gn_197901-201412-clim.nc) }\end{array}$ \\
\hline 6.2 & pa-futArcSIC-ext & $\begin{array}{l}\text { siconc_input4MIPs_SSTsAndSeaIce_PAMIP_UCI-fut2CArctic-1-0_gn_clim.nc } \\
\text { (sithick_input4MIPs_SSTsAndSeaIce_PAMIP_UCI-fut2CArctic-1-0_gn_clim.nc) }\end{array}$ \\
\hline 6.3 & pa-futAntSIC-ext & $\begin{array}{l}\text { siconc_input4MIPs_SSTsAndSeaIce_PAMIP_UCI-fut2CAntarctic-1-0_gn_clim.nc } \\
\text { (sithick_input4MIPs_SSTsAndSeaIce_PAMIP_UCI-fut2CAntarctic-1-0_gn_clim.nc) }\end{array}$ \\
\hline
\end{tabular}

\section{Start date and length of simulations}

Experiments 1 to 4 should start on 1 April 2000 and run for 14 months, with the first 2 months ignored to allow for an initial model spin-up. Experiment 6 starts at the same time but extends to 100 years. Experiment 5 starts on 1 January 1979 and ends on 31 December 2014 in accordance with the AMIP protocol (Eyring et al., 2016).

\section{Initial conditions and ensemble generation}

Initial conditions for atmosphere-only experiments $(1,3$ and 4) should be based on the AMIP simulation for 1 April 2000 if possible, though any suitable start dump may be used, noting that the first 2 months of the simulations will be ignored. Initial conditions for the coupled experiments ( 2 and 6) should be based on 1 April 2000 from the CMIP6 historical simulation (Eyring et al., 2016). Ideally, different ocean states will be sampled by using different ensemble members of the historical simulation if these are available. Large ensembles $(\sim 100$ members $)$ are requested in order to obtain statistically robust results, since models typically simulate a small atmospheric response to sea ice relative to internal variability (Screen et al., 2014; Mori et al., 2014). We note that this may not be the case in reality, since models underestimate the signal-to-noise ratio in seasonal and interannual forecasts of the NAO (Scaife et al., 2014; Eade et al., 2014; Dunstone et al., 2016). The results are not expected to be particularly sensitive to the way in which ensemble members are generated, and any suitable method may be used but should be documented.

\section{Frequency of boundary conditions}

SST and sea ice boundary conditions are specified as monthly means and should be interpolated to the required model time step (as is standard practice). Daily boundary conditions might strengthen some of the signals, but the additional complexity was considered unnecessary for assessing the physical processes and signals of interest here.

\section{Constraining sea ice in coupled models}

It is important that the sea ice fields used in the coupled model experiment (set 2) are close to those used in the atmosphere-only simulations ( 1 and 4 ), so that differences are not caused by different sea ice forcing fields. It is therefore recommended that sea ice concentrations are nudged into the coupled model, with a strong relaxation timescale (or equivalent restoring flux) of 1 day. However, decadal and longer-timescale responses investigated in experiment 6 could potentially be contaminated by undesired responses to the nudging increments. It is therefore recommended that a weaker relaxation timescale of 2 months is used for these. This is similar to the DCPP component $\mathrm{C}$ experiments (Boer et al., 2016) which investigate the response to AMV and PDV, and technical issues relating to nudging are discussed in Technical Note 2 available from the DCPP website (http://www.wcrp-climate.org/dcp-overview, last access: 20 March 2019). Similar to the DCPP experiments, groups are recommended to monitor their experiments and take action, perhaps by reducing the relaxation timescale or applying balancing increments, to avoid unrealistic responses. Alternatively, appropriately calibrated long-wave fluxes applied to the sea ice model (following Deser et al., 2015) may also be used in experiment 6 , but the calibration procedure should be documented. We note that all approaches for constraining sea ice are imperfect, but experiment 6 will nevertheless provide important information on the transient response that is not available from the other experiments. 
Table A2. List of models used to construct the forcing fields.

\begin{tabular}{|c|c|}
\hline Acronym & Research centre \\
\hline ACCESS1-0 & \multirow{2}{*}{ Commonwealth Scientific and Industrial Research Organisation, and Bureau of Meteorology, Australia } \\
\hline ACCESS1-3 & \\
\hline bcc-csm1-1 & \multirow{2}{*}{ Beijing Climate Center, China } \\
\hline bcc-csm1-1-m & \\
\hline CanESM2 & Canadian Centre for Climate Modelling and Analysis, Canada \\
\hline CCSM4 & \multirow{3}{*}{ National Center for Atmospheric Research, USA } \\
\hline CESM1-BGC & \\
\hline CESM1-CAM5 & \\
\hline CMCC-CM & \multirow{2}{*}{ Centro Euro-Mediterraneo per I Cambiamenti Climatici, Italy } \\
\hline CMCC-CMS & \\
\hline CNRM-CM5 & Centre National de Recherches Météorologiques/Centre Européen de Recherche et Formation Avancées en Calcul Scientifique, France \\
\hline CSIRO-Mk3-6-0 & $\begin{array}{l}\text { Commonwealth Scientific and Industrial Research Organisation, in collaboration with the Queensland Climate Change Centre of Excel- } \\
\text { lence, Australia }\end{array}$ \\
\hline EC-EARTH & EC-Earth \\
\hline FIO-ESM & The First Institute of Oceanography, China \\
\hline GFDL-CM3 & \multirow{3}{*}{ US Department of Commerce/National Oceanic and Atmospheric Administration/Geophysical Fluid Dynamics Laboratory, USA } \\
\hline GFDL-ESM2G & \\
\hline GFDL-ESM2M & \\
\hline GISS-E2-H & \multirow[t]{2}{*}{ National Aeronautics and Space Administration/Goddard Institute for Space Studies, USA } \\
\hline GISS-E2-R & \\
\hline HadGEM2-CC & \multirow{2}{*}{ Met Office Hadley Centre, UK } \\
\hline HadGEM2-ES & \\
\hline inmcm4 & Institute for Numerical Mathematics, Russia \\
\hline IPSL-CM5A-LR & \multirow{3}{*}{ Institut Pierre Simon Laplace, France } \\
\hline IPSL-CM5A-MR & \\
\hline IPSL-CM5B-LR & \\
\hline MIROC5 & $\begin{array}{l}\text { Center for Climate System Research (University of Tokyo), National Institute for Environmental Studies, and Frontier Research Center for } \\
\text { Global Change, Japan }\end{array}$ \\
\hline MPI-ESM-LR & \multirow{2}{*}{ Max Planck Institute for Meteorology, Germany } \\
\hline MPI-ESM-MR & \\
\hline MRI-CGCM3 & Meteorological Research Institute, Japan \\
\hline NorESM1-M & \multirow{2}{*}{ Norwegian Climate Centre, Norway } \\
\hline NorESM1-ME & \\
\hline
\end{tabular}




\section{Sea ice thickness}

Some participating groups may not able to specify sea ice thickness. Hence, in the atmosphere-only experiments (except 1.9 and 1.10), sea ice thickness should be treated in the same way as in the AMIP DECK simulation. We note that there is not a common protocol, but in practice the sea ice thickness will be at least $2 \mathrm{~m}$ so that differences in surface fluxes between models will be small. Experiments 1.9 and 1.10 are designed to investigate the impacts of future sea ice thickness changes, and sea ice thickness should be constrained with a relaxation timescale (or equivalent flux) of 5 days. Groups that are able to specify sea ice thickness are requested to do so for the coupled model experiments, using values from the equivalent atmosphere-only simulations for experiment 2 , and the fields provided by PAMIP for experiment 6. If sea ice thickness cannot be specified, then it should be left free to evolve in the coupled model experiments.

\section{SST forcing fields for experiment set 4}

Experiments 4.1 and 4.2 repeat experiments 1.1 and 1.6 but with present-day SSTs taken from the coupled model experiment 2.1 instead of from observations. This allows the sensitivity to background SSTs to be investigated and the role of coupling to be isolated (assuming signals add linearly). Experiments 4.1 and 4.2 use the same SIC forcing fields as experiments 1.1 and 1.6, but participants will need to create their own monthly mean present-day SST forcing fields by taking the ensemble average for each month from experiment 2.1. Experiment 4.2 requires SSTs to be specified in regions where the sea ice has been removed. It is critically important that the change in SST in these regions between experiments 4.2 and 4.1 is exactly the same as that between experiments 1.6 and 1.1, so that the forcings are identical. Hence, in regions where sea ice has been removed, SST in experiment 4.2 should be set equal to the SST in experiment 4.1 plus the difference in SST between experiments 1.6 and 1.1 (i.e. experiment 1.6 minus experiment 1.1). 
Author contributions. All authors contributed to the design of the experimental protocol. DMS led the writing with comments from all authors. YP created the forcing data in collaboration with DMS, JAS and TJ.

Competing interests. The authors declare that they have no conflict of interest.

Acknowledgements. The author give thanks to the US CLIVAR Working Group on Arctic Change and the Aspen Global Change Institute (AGCI) for hosting workshops which contributed to PAMIP planning, with funding from NASA, NSF, NOAA and DOE. Doug M. Smith was supported by the joint DECC/Defra Met Office Hadley Centre Climate Programme (GA01101) and the EU H2020 APPLICATE project (GA727862). James A. Screen was supported by NERC grant NE/R005125/1. NCAR is sponsored by the National Science Foundation. Javier García-Serrano was supported by the EU H2020 PRIMAVERA (GA641727). Jin-Ho Yoon was supported by the funding from the Korean Polar Research Institute through grant PE16100. Daniela Matei was supported by the EU H2020 Blue-Action (GA 727852) and BMBF project CLIMPRE InterDec (FKZ:01LP1609A). Jinro Ukita was supported by ArCS and InderDec. The authors thank Yannick Peings for creating the forcing fields.

Review statement. This paper was edited by Julia Hargreaves and Lauren Gregoire and reviewed by two anonymous referees.

\section{References}

Acosta Navarro, J. C., Varma, V., Riipinen, I., Seland, Ø., Kirkevåg, A., Struthers, H., Iversen, T., Hansson H.-C., and Ekman, A. M. L.: Amplification of Arctic warming by past air pollution reductions in Europe, Nat. Geosci., 9, 277-281, https://doi.org/10.1038/ngeo2673, 2016.

Alexander, M. A., Bhatt, U. S., Walsh, J. E., Timlin, M. S., Miller, J. S., and Scott, J. D.: The atmospheric response to realistic Arctic sea ice anomalies in an AGCM during winter, J. Clim., 17, 890905, 2004

Armour, K. C., Marshall, J., Scott, J., Donohoe A., and Newsom, E. R.: Southern Ocean warming delayed by circumpolar upwelling and equatorward transport, Nat. Geosci., 9, 549-554, https://doi.org/10.1038/ngeo2731, 2016.

Bader, J., Flügge, M., Kvamstø, N. G., Mesquita M. D. S., and Voigt, A.: Atmospheric winter response to a projected future Antarctic sea-ice reduction: a dynamical analysis, Clim. Dynam., 40, 2707-2718, 2013.

Balmaseda, M. A., Ferranti, L., Molteni F., and Palmer, T. N.: Impact of 2007 and 2008 Arctic ice anomalies on the atmospheric circulation: Implciations for long-range predictions, Q. J. Roy. Meteor. Soc., 136, 1655-1664, 2010.

Barnes, E. A. and Screen, J. A.: The impact of Arctic warming on the midlatitude jet-stream: Can it? Has it? Will it?, Clim. Change, 6, 277-286, https://doi.org/10.1002/wcc.337, 2015.
Bindoff, N. L., Stott, P. A., Achuta Rao, K. M., Allen, M. R., Gillett, N., Gutzler, D., Hansingo, K., Hegerl, G., Hu, Y., Jain, S., Mokhov, I. I., Overland, J., Perlwitz, J., Sebbari R., and Zhang, X.: Detection and Attribution of Climate Change: from Global to Regional, in: Climate Change 2013: The Physical Science Basis, Contribution of Working Group I to the Fifth Assessment Report of the Intergovernmental Panel on Climate Change, edited by: Stocker, T. F., Qin, D., Plattner, G.-K., Tignor, M., Allen, S. K., Boschung, J., Nauels, A., Xia, Y., Bex, V., and Midgley, P. M., Cambridge University Press, Cambridge, UK, New York, NY, USA, 2013.

Bintanja, R., van Oldenborgh, G. J., Drijfhout, S. S., Wouters, B., and Katsman, C. A.: Important role for ocean warming and increased ice-shelf melt in Antarctic sea-ice expansion, Nat. Geosci., 6, 376-379, 2013.

Blackport, R. and Kushner, P.: The transient and equilibrium climate response to rapid summertime sea ice loss in CCSM4, J. Clim., 29, 401-417, https://doi.org/10.1175/JCLI-D-15-0284.1, 2016.

Blackport, R. and P. J. Kushner: Isolating the atmospheric circulation response to Arctic sea ice loss in the coupled climate system, J. Clim., 30, 2163-2185, https://doi.org/10.1175/JCLI-D16-0257.1, 2017.

Boer, G. J., Smith, D. M., Cassou, C., Doblas-Reyes, F., Danabasoglu, G., Kirtman, B., Kushnir, Y., Kimoto, M., Meehl, G. A., Msadek, R., Mueller, W. A., Taylor, K. E., Zwiers, F., Rixen, M., Ruprich-Robert, Y., and Eade, R.: The Decadal Climate Prediction Project (DCPP) contribution to CMIP6, Geosci. Model Dev., 9, 3751-3777, https://doi.org/10.5194/gmd-9-3751-2016, 2016.

Bracegirdle, T. J. and Stephenson, D. B.: On the robustness of emergent constraints used in multimodel climate change projections of Arctic warming, J. Clim. 26, 669-678, 2013.

Cassano, E. N., Cassano, J. J., Higgins, M. E., and Serreze, M. C.: Atmospheric impacts of an Arctic sea ice minimum as seen in the Community Atmosphere Model, Int. J. Climatol., 34, 766-779, https://doi.org/10.1002/joc.3723, 2014.

Chen, H. W., Zhang, F., and Alley, R. B.: The robustness of midlatitude weather pattern changes due to Arctic sea ice loss, J. Climate, 29, 7831-7849, https://doi.org/10.1175/JCLI-D-160167.1, 2016.

Chiang, J. C. H. and Bitz, C. M.: Influence of high latitude ice on the marine intertropical convergence zone, Clim. Dynam., 25, 477496, https://doi.org/10.1007/s00382-005-0040-5, 2005.

Chylek, P., Folland, C. K., Lesins, G., Dubey, M. K., and Wang, M.: Arctic air temperature change amplification and the Atlantic Multidecadal Oscillation, Geophys. Res. Lett., 36, L14801, https://doi.org/10.1029/2009GL038777, 2009.

Cohen, J. and Entekhabi, D.: Eurasian snow cover variability and Northern Hemisphere climate predictability, Geophys. Res. Lett., 26, 345-348, https://doi.org/10.1029/1998GL900321, 1999.

Cohen, J., Jones, J., Furtado, J. C., and Tziperman, E.: Warm Arctic, cold continents: A common pattern related to Arctic sea ice melt, snow advance, and extreme winter weather, Oceanography, 26, 150-160, https://doi.org/10.5670/oceanog.2013.70, 2013.

Cohen, J., Screen, J. A., Furtado, J. C., Barlow, M., Whittleston, D., Coumou, D., Francis, J., Dethloff, K., Entekhabi, D., Overland, J., and Jones, J.: Recent Arctic amplification and extreme mid-latitude weather, Nat. Geosci., 7, 627-637, https://doi.org/10.1038/ngeo2234, 2014. 
Collins, M., Chandler, R. E., Cox, P. M., Huthnance, J. M., Rougier, J., and Stephenson, D. B.: Quantifying future climate change, Nat. Clim. Change, 2, 403-409, https://doi.org/10.1038/nclimate1414, 2012.

Collins, M., Knutti, R., Arblaster, J., Dufresne, J.-L., Fichefet, T., Friedlingstein, P., Gao, X., Gutowski, W. J., Johns, T., Krinner, G., Shongwe, M., Tebaldi, C., Weaver A. J., and Wehner, M.: Long-term Climate Change: Projections, Commitments and Irreversibility, in: Climate Change 2013: The Physical Science Basis, Contribution of Working Group I to the Fifth Assessment Report of the Intergovernmental Panel on Climate Change, edited by: Stocker, T. F., Qin, D., Plattner, G.-K., Tignor, M., Allen, S. K., Boschung, J., Nauels, A., Xia, Y., Bex, V., and Midgley, P. M., Cambridge University Press, Cambridge, UK, New York, NY, USA, 2013.

Collins, W. J., Lamarque, J.-F., Schulz, M., Boucher, O., Eyring, V., Hegglin, M. I., Maycock, A., Myhre, G., Prather, M., Shindell, D., and Smith, S. J.: AerChemMIP: quantifying the effects of chemistry and aerosols in CMIP6, Geosci. Model Dev., 10, 585607, https://doi.org/10.5194/gmd-10-585-2017, 2017.

Cowtan, K. and Way, R. G.: Coverage bias in the HadCRUT4 temperature series and its impact on recent temperature trends, Q. J. Roy. Meteor. Soc., 133, 459-477, 2013.

Cvijanovic, I., Santer, B. D., Bonfils, C., Lucas, D. D., Chiang, J. C. H., and Zimmerman, S.: Future loss of Arctic sea-ice cover could drive a substantial decrease in California's rainfall, Nature Commun., 8, 1947, https://doi.org/10.1038/s41467-017-019074, 2017.

Deser, C., Tomas, R., Alexander, M., and Lawrence, D.: The seasonal atmospheric response to projected sea ice loss in the late twenty-first century, J. Clim., 23, 333-351, 2010.

Deser, C., Tomas, R. A., and Sun, L.: The role of oceanatmosphere coupling in the zonal-mean atmospheric response to Arctic sea ice loss, J. Climate, 28, 2168-2186, https://doi.org/10.1175/JCLI-D-14-00325.1, 2015.

Deser, C., Sun, L., Tomas, R. A., and Screen, J.: Does oceancoupling matter for the northern extra-tropical response to projected Arctic sea ice loss? Geophys. Res. Lett., 43, 2149-2157, https://doi.org/10.1002/2016GL067792, 2016.

Ding, Q., Wallace, J. M., Battisti, D. S., Steig, E. J., Galland, A. J. E., Kim, H.-J., and Geng, L.: Tropical forcing of the recent rapid Arctic warming in northeastern Canada and Greenland, Nature, 509, 209-212, https://doi.org/10.1038/nature13260, 2014.

Ding, Q., Schweiger, A., L'Heureux, M., Battisti, D. S., Po-Chedley, S., Johnson, N. C., Blanchard-Wrigglesworth, E., Harnos, K., Zhang, Q., Eastman, R., and Steig, E. J.: Influence of highlatitude atmospheric circulation changes on summertime Arctic sea ice, Nat. Clim. Change, 7, 289-295, 2017.

Dunstone, N. J., Smith, D. M., Scaife, A. A., Hermanson, L., Eade, R., Robinson, N., Andrews, M., and Knight, J.: Skilful predictions of the winter North Atlantic Oscillation one year ahead, Nat. Geosci., 9, 809-814, https://doi.org/10.1038/NGEO2824, 2016.

Eade, R., Smith, D. M., Scaife, A. A., Wallace, E., Dunstone, N., Hermanson, L., and Robinson, N.: Do seasonal to decadal climate predictions underestimate the predictability of the real world?, Geophys. Res. Lett., 41, 5620-5628, https://doi.org/10.1002/2014GL061146, 2014.
England, M., Polvani, L., and Sun, L.: Contrasting the Antarctic and Arctic atmospheric responses to projected sea ice loss in the late 21st Century Contrasting the Antarctic and Arctic atmospheric responses to projected sea ice loss in the late 21 st Century, J. Climate, 31, 6353-6370, https://doi.org/10.1175/JCLI-D17-0666.1, 2018

Eyring, V., Bony, S., Meehl, G. A., Senior, C. A., Stevens, B., Stouffer, R. J., and Taylor, K. E.: Overview of the Coupled Model Intercomparison Project Phase 6 (CMIP6) experimental design and organization, Geosci. Model Dev., 9, 1937-1958, https://doi.org/10.5194/gmd-9-1937-2016, 2016.

Feldstein, S. and Lee, S.: Intraseasonal and interdecadal jet shifts in the Northern Hemisphere: The role of warm pool tropical convection and sea ice, J. Climate, 27, 6497-6518, https://doi.org/10.1175/JCLI-D-14-00057.1, 2014.

Francis, J. A. and Vavrus, S. J.: Evidence linking Arctic amplification to extreme weather in mid-latitudes, Geophys. Res. Lett., 39, L06801, https://doi.org/10.1029/2012GL051000, 2012.

Furtado, J. C., Cohen, J. L., Butler, A. H., Riddle, E. E., and Kumar, A.: Eurasian snow cover variability and links to winter climate in the CMIP5 models, Clim. Dynam., 45, 2591-2605, 2015.

Fyfe, J. C., von Salzen, K., Gillett, N. P., Arora, V. K., Flato, G. M., and McConnell, J. R.: One hundred years of Arctic surface temperature variation due to anthropogenic influence, Sci. Rep., 3, 2645, https://doi.org/10.1038/srep02645, 2013.

Gagné, M.-È., Fyfe, J. C., Gillett, N. P., Polyakov, I. V., and Flato, G. M.: Aerosol-driven increase in Arctic sea ice over the middle of the twentieth century, Geophys. Res. Lett., 44, 7338-7346, https://doi.org/10.1002/2016GL071941, 2017.

García-Serrano, J., Frankignoul, C., Gastineau, G., and de la Cámara, A.: On the predictability of the winter Euro-Atlantic climate: lagged influence of autumn Arctic sea ice, J. Clim., 28, 5195-5216, 2015.

García-Serrano, J., Frankignoul, C., King, M. P., Arribas, A., Gao, Y., Guemas, V., Matei, D., Msadek, R., Park, W., and Sanchez-Gomez, E.: Multi-model assessment of linkages between eastern Arctic sea-ice variability and the Euro-Atlantic atmospheric circulation in current climate, Clim. Dynam., 49, 2407, https://doi.org/10.1007/s00382-016-3454-3, 2017

Gastineau, G., García-Serrano, J., and Frankignoul, C.: The influence of autumnal Eurasian snow cover on climate and its link with Arctic sea ice cover, J. Clim., 19, 7599-7619, 2017.

Gerber, E. P. and Manzini, E.: The Dynamics and Variability Model Intercomparison Project (DynVarMIP) for CMIP6: assessing the stratosphere-troposphere system, Geosci. Model Dev., 9, 34133425, https://doi.org/10.5194/gmd-9-3413-2016, 2016.

Graversen, R. G. and Wang, M.: Polar amplification in a coupled climate model with locked albedo, Clim. Dynam., 33, 629-643, 2009.

Graversen, R., Mauritsen, T., Tjernström, M., Källén, E., and Svensson, G.: Vertical structure of recent Arctic warming, Nature, 451, 53-56, 2008.

Gillett, N. P., Shiogama, H., Funke, B., Hegerl, G., Knutti, R., Matthes, K., Santer, B. D., Stone, D., and Tebaldi, C.: The Detection and Attribution Model Intercomparison Project (DAMIP v1.0) contribution to CMIP6, Geosci. Model Dev., 9, 3685-3697, https://doi.org/10.5194/gmd-9-3685-2016, 2016.

Hall, A.: The role of surface albedo feedback in climate, J. Clim., 17, 1550-1568, 2004. 
Hall, A. and Qu, X.: Using the current seasonal cycle to constrain the snow albedo feedback in future climate change, Geophys. Res. Lett., 33, L03502, https://doi.org/10.1029/2005GL025127, 2006.

Hansen, J., Ruedy, R., Sato, M., and Lo, K.: Global surface temperature change, Rev. Geophys., 48, RG4004, https://doi.org/10.1029/2010RG000345, 2010.

Haustein, K., Allen, M. R., Forster, P. M., Otto, F. E. L., Mitchell, D. M., Matthews, H. D., and Frame, D. J.: A real-time Global Warming Index, Sci. Rep., 7, 15417, https://doi.org/10.1038/s41598-017-14828-5, 2017.

Hind, A., Zhang, Q., and Brattström, G.: Problems encountered when defining Arctic amplification as a ratio, Sci. Rep., 6, 30469, https://doi.org/10.1038/srep30469, 2016.

Holland, M. and Bitz, C.: Polar amplification of climate change in coupled models, Clim. Dynam., 21, 221-232, 2003.

Honda, M., Yamazaki, K., Tachibana, Y., and Takeuchi, K.: Influence of Okhotsk sea-ice extent on atmospheric circulation, Geophys. Res. Lett., 23, 3595-3598, https://doi.org/10.1029/96GL03474, 1996.

Honda, M., Inoue, J., and Yamane, S.: Influence of low Arctic sea ice minima on anomalously cold Eurasian winters. Geophys. Res. Lett., 36, L08707, https://doi.org/10.1029/2008GL037079, 2009.

Huang, Y., Xia, Y., and Tan, X.: On the pattern of $\mathrm{CO}_{2}$ radiative forcing and poleward energy transport, J. Geophys. Res.-Atmos., 122, 10578-10593, https://doi.org/10.1002/2017JD027221, 2017

Jaiser, R., Dethloff, K., and Handorf, D.: Stratospheric response to Arctic sea ice retreat and associated planetary wave propagation changes, Tellus A, 65, 19375, https://doi.org/10.3402/tellusa.v65i0.19375, 2013.

Jones, C. D., Arora, V., Friedlingstein, P., Bopp, L., Brovkin, V., Dunne, J., Graven, H., Hoffman, F., Ilyina, T., John, J. G., Jung, M., Kawamiya, M., Koven, C., Pongratz, J., Raddatz, T., Randerson, J. T., and Zaehle, S.: C4MIP - The Coupled Climate-Carbon Cycle Model Intercomparison Project: experimental protocol for CMIP6, Geosci. Model Dev., 9, 2853-2880, https://doi.org/10.5194/gmd-9-2853-2016, 2016a.

Jones, J. M., Gille, S. T., Goosse, H., Abram, N. J., Canziani, P. O., Charman, D. J., Clem, K. R., Crosta, X., de Lavergne, C., Eisenman, I., England, M. H., Fogt, R. L., Frankcombe, L. M., Marshall, G. J., Masson-Delmotte, V., Morrison, A. K., Orsi, A. J., Raphael, M. N., Renwick, J. A., Schneider, D. P., Simpkins, G. R., Steig, E. J., Stenni, B., Swingedouw, D., and Vance, T. R.: Assessing recent trends in high-latitude Southern Hemisphere surface climate, Nat. Clim. Change, 6, 917-926, https://doi.org/10.1038/nclimate3103, 2016b.

Kageyama, M., Braconnot, P., Harrison, S. P., Haywood, A. M., Jungclaus, J. H., Otto-Bliesner, B. L., Peterschmitt, J.-Y., AbeOuchi, A., Albani, S., Bartlein, P. J., Brierley, C., Crucifix, M., Dolan, A., Fernandez-Donado, L., Fischer, H., Hopcroft, P. O., Ivanovic, R. F., Lambert, F., Lunt, D. J., Mahowald, N. M., Peltier, W. R., Phipps, S. J., Roche, D. M., Schmidt, G. A., Tarasov, L., Valdes, P. J., Zhang, Q., and Zhou, T.: The PMIP4 contribution to CMIP6 - Part 1: Overview and overarching analysis plan, Geosci. Model Dev., 11, 1033-1057, https://doi.org/10.5194/gmd-11-1033-2018, 2018.
Karl, T. R., Arguez, A., Huang, B., Lawrimore, J. H., McMahon, J. R., Menne, M. J., Peterson, T. C., Vose, R. S., and Zhang, H.M.: Possible artifacts of data biases in the recent global surface warming hiatus, Science, 348, 1469-1472, 2015.

Khodri, M., Leclainche, Y., Ramstein, G., Braconnot, P., Marti, O., and Cortijo, E.: Simulating the amplification of orbital forcing by ocean feedbacks in the last glaciations, Nature, 410, 570-574, 2001.

Kidston, J., Taschetto, A. S., Thompson, D. W. J., and England, M. H.: The influence of Southern Hemisphere sea-ice extent on the latitude of the mid-latitude jet stream, Geophys. Res. Lett., 38, L15804, https://doi.org/10.1029/2011GL048056, 2011.

Kim, B. M., Son, S. W., Min, S. K., Jeong, J. H., Kim, S. J., Zhang, X., Shim, T., and Yoon, J. H.: Weakening of the stratospheric polar vortex by Arctic sea-ice loss, Nat. Commun., 5, 4646, https://doi.org/10.1038/ncomms5646, 2014.

Kravitz, B., Robock, A., Tilmes, S., Boucher, O., English, J. M., Irvine, P. J., Jones, A., Lawrence, M. G., MacCracken, M., Muri, H., Moore, J. C., Niemeier, U., Phipps, S. J., Sillmann, J., Storelvmo, T., Wang, H., and Watanabe, S.: The Geoengineering Model Intercomparison Project Phase 6 (GeoMIP6): simulation design and preliminary results, Geosci. Model Dev., 8, 33793392, https://doi.org/10.5194/gmd-8-3379-2015, 2015.

Kretschmer, M., Coumou, D., Angel, L., Barlow, M., Tziperman, E., and Cohen, J.: More frequent weak stratospheric polar vortex states linked to mid-latitude cold extremes, B. Am. Meteorol. Soc., 99, 49-60, https://doi.org/10.1175/BAMS-D-160259.1, 2018.

Kug, J.-S., Jeong, J.-H., Jang, Y.-S., Kim, B.-M., Folland, C. K., Min, S.-K., and Son, S.-W.: Two distinct influences of Arctic warming on cold winters over North America and East Asia, Nat. Geosci., 8, 759-762, https://doi.org/10.1038/ngeo2517, 2015.

Kumar, A., Perlwitz, J., Eischeid, J., Quan, X., Xu, T., Zhang, T., Hoerling, M., Jha, B., and Wang, W.: Contribution of sea ice loss to Arctic amplification, Geophys. Res. Lett., 37, L21701, https://doi.org/10.1029/2010GL045022, 2010.

Li, X., Holland, D. M., Gerber, E. P., and Yoo, C.: Impacts of the north and tropical Atlantic Ocean on the Antarctic Peninsula and sea ice, Nature, 505, 538-542, https://doi.org/10.1038/nature12945, 2014.

Liu, J. P., Curry, J. A., Wang, H., Song, M., and Horton, R. M.: Impact of declining Arctic sea ice on winter snowfall, P. Natl. Acad. Sci. USA, 109, 4074-4079, https://doi.org/10.1073/pnas.1114910109, 2012.

Manabe, S. and Stouffer, R.: Multiple-century response of a coupled ocean-atmosphere model to an increase of atmospheric carbondioxide, J. Clim., 7, 5-23, 1994.

Manabe, S. and Wetherald, R. T.: On the distribution of climate change resulting from an increase in $\mathrm{CO}_{2}$ content of the atmosphere, J. Atmos. Sci., 37, 99-118, 1980.

Masson-Delmotte, V., Schulz, M., Abe-Ouchi, A., Beer, J., Ganopolski, A., González Rouco, J. F., Jansen, E., Lambeck, K., Luterbacher, J., Naish, T., Osborn, T., Otto-Bliesner, B., Quinn, T., Ramesh, R., Rojas, M., Shao, X., and Timmermann, A.: Information from Paleoclimate Archives, in: Climate Change 2013: The Physical Science Basis, Contribution of Working Group I to the Fifth Assessment Report of the Intergovernmental Panel on Climate Change, edited by: Stocker, T. F., Qin, D., Plattner, G.K., Tignor, M., Allen, S. K., Boschung, J., Nauels, A., Xia, Y., 
Bex, V., and Midgley, P. M., Cambridge University Press, Cambridge, UK, New York, NY, USA, 2013.

McCusker, K. E., Fyfe, J. C., and Sigmond, M.: Twentyfive winters of unexpected Eurasian cooling unlikely due to Arctic sea ice loss, Nat. Geosci., 9, 838-842, https://doi.org/10.1038/ngeo2820, 2016.

McCusker, K. E., Kushner, P., Fyfe, J. C., Sigmond, M., Kharin, V. V., and Bitz, C. M.: Remarkable separability of circulation response to Arctic sea ice loss and greenhouse gas forcing, Geophys. Res. Lett., 44, 7955-7964, https://doi.org/10.1002/2017g1074327, 2017.

Menéndez, C., Serafini, V., and Le Treut, H.: The effect of sea-ice on the transient atmospheric eddies of the Southern Hemisphere, Clim. Dynam., 15, 659-671, https://doi.org/10.1007/s003820050308, 1999.

Mori, M., Watanabe, M., Shiogama, H., Inoue, J., and Kimoto, M.: Robust arctic sea ice influence on the frequent Eurasian cold winters in past decades, Nat. Geosci., 7, 869-873, 2014.

Morice, C. P., Kennedy, J. J., Rayner, N. A., and Jones, P. D.: Quantifying uncertainties in global and regional temperature change using an ensemble of observational estimates: the HadCRUT4 data set, J. Geophys. Res., 117, D08101, https://doi.org/10.1029/2011JD017187, 2012.

Nakamura, T., Yamazaki, K., Iwamoto, K., Honda, M., Miyoshi, Y., Ogawa, Y., and Ukita, J.: A negative phase shift of the winter AO/NAO due to the recent Arctic sea-ice reduction in late autumn, J. Geophys. Res.-Atmos., 120, 3209-3227, https://doi.org/10.1002/2014JD022848, 2015.

Nowicki, S. M. J., Payne, A., Larour, E., Seroussi, H., Goelzer, H., Lipscomb, W., Gregory, J., Abe-Ouchi, A., and Shepherd, A.: Ice Sheet Model Intercomparison Project (ISMIP6) contribution to CMIP6, Geosci. Model Dev., 9, 4521-4545, https://doi.org/10.5194/gmd-9-4521-2016, 2016.

Ogawa, F., Keenlyside, N., Gao, Y., Koenigk, T., Yang, S., Suo, L., Wang, T., Gastineau, G., Nakamura, T., Cheung, H. N., Omrani, N.-E., Ukita, J., and Semenov, V.: Evaluating impacts of recent Arctic sea ice loss on the northern hemisphere winter climate change, Geophys. Res. Lett., 45, 3255-3263, https://doi.org/10.1002/2017GL076502, 2018.

O’Neill, B. C., Tebaldi, C., van Vuuren, D. P., Eyring, V., Friedlingstein, P., Hurtt, G., Knutti, R., Kriegler, E., Lamarque, J.-F., Lowe, J., Meehl, G. A., Moss, R., Riahi, K., and Sanderson, B. M.: The Scenario Model Intercomparison Project (ScenarioMIP) for CMIP6, Geosci. Model Dev., 9, 3461-3482, https://doi.org/10.5194/gmd-9-3461-2016, 2016.

Orsolini, Y. J., Senan, R., Benestad, R. E., and Melsom, A.: Autumn atmospheric response to the 2007 low Arctic sea ice extent in coupled ocean-atmosphere hindcasts, Clim. Dynam., 38, 24372448, https://doi.org/10.1007/s00382-011-1169-z, 2012.

Oudar, T., Sanchez-Gomez, E., Chauvin, F., Cattiaux, J., Terray, L., and Cassou, C.: Respective roles of direct GHG radiative forcing and induced Arctic sea ice loss on the Northern Hemisphere atmospheric circulation, Clim. Dynam., 49, 3693-3713, https://doi.org/10.1007/s00382-017-3541-0, 2017.

Overland, J. E., Wood, K. R., and Wang, M.: Warm Arctic-cold continents: Climate impacts of the newly open Arctic Sea, Polar Res., 30, 15787, https://doi.org/10.3402/polar.v30i0.15787, 2011.
Overland, J., Francis, J., Hall, R., Hanna, E., Kim, S., and Vihma, T.: The melting arctic and Mid-latitude weather patterns: Are they connected?, J. Clim., 28, 7917-7932, https://doi.org/10.1175/JCLI-D-14-00822.1, 2015.

Overland, J. E., Dethloff, K., Francis, J. A., Hall, R. J., Hanna, E., Kim, S.-J., Screen, J. A., Shepherd, T. G., and Vihma, T.: Nonlinear response of midlatitude weather to the changing Arctic, Nat. Clim. Change, 6, 992-999, 2016.

Overpeck, J., Hughen, K., Hardy, D., Bradley, R., Case, R., Douglas, M., Finney, B., Gajewski, K., Jacoby, G., Jennings, A., Lamoureux, S., Lasca, A., MacDonald, G., Moore, J., Retelle, M., Smith, S., Wolfe, A., and Zielinski, G.: Arctic environmental change of the last four centuries, Science, 278, 1251-1256, 1997.

Pedersen, R., Cvijanovic, I., Langen, P., and Vinther, B.: The impact of regional Arctic sea ice loss on atmospheric circulation and the NAO, J. Climate, 29, 889-902, https://doi.org/10.1175/JCLI-D15-0315.1, 2016.

Peings, Y. and Magnusdottir, G.: Response of the wintertime Northern Hemispheric atmospheric circulation to current and projected Arctic sea ice decline: a numerical study with CAM5, J. Climate, 27, 244-264, 2014.

Perlwitz, J., Hoerling, M., and Dole, R.: Arctic Tropospheric Warming: Causes and Linkages to Lower Latitudes, J. Climate, 28 , 2154-2167, https://doi.org/10.1175/JCLI-D-14-00095.1, 2015.

Petoukhov, V. and Semenov, V. A.: A link between reduced Barents-Kara sea ice and cold winter extremes over northern continents, J. Geophys. Res., 115, D21111, https://doi.org/10.1029/2009JD013568, 2010.

Petrie, R. E., Shaffrey, L. C., and Sutton, R. T.: Atmospheric Impact of Arctic Sea Ice Loss in a Coupled Ocean-Atmosphere Simulation, J. Climate, 28, 9606-9622, https://doi.org/10.1175/JCLID-15-0316.1, 2015.

Pithan, F. and Mauritsen, T.: Arctic amplification dominated by temperature feedbacks in contemporary climate models, Nat Geosci., 7, 181-184, https://doi.org/10.1038/ngeo2071, 2014.

Purich, A., England, M. H., Cai, W., Chikamoto, Y., Timmermann, A., Fyfe, J. C., Frankcombe, L., Meehl, G. A., and Arblaster, J. M.: Tropical Pacific SST drivers of recent Antarctic Sea ice trends, J. Clim., 29, 8931-8948, https://doi.org/10.1175/JCLI-D16-0440.1, 2016.

Raphael, M. N., Hobbs, W., and Wainer, I.: The effect of Antarctic sea ice on the Southern Hemisphere atmosphere during the southern summer, Clim. Dynam., 36, 1403-1417, https://doi.org/10.1007/s00382-010-0892-1, 2011.

Raphael, M. N., Marshall, G. J., Turner, J., Fogt, R., Schneider, D. P., Dixon, D. A., Hosking, J. S., Jones, J., and Hobbs, W.: The Amundsen Sea Low: Variability, change and impact on Antarctic climate, B. Am. Meteorol. Soc., 97, 111-121, 2015.

Rinke, A., Dethloff, K., Dorn, W., Handorf, D., and Moore, J. C.: Simulated Arctic atmospheric feedbacks associated with late summer sea ice anomalies, J. Geophys. Res.-Atmos., 118, 7698 7714, https://doi.org/10.1002/jgrd.50584, 2013.

Ruane, A. C., Teichmann, C., Arnell, N. W., Carter, T. R., Ebi, K. L., Frieler, K., Goodess, C. M., Hewitson, B., Horton, R., Kovats, R. S., Lotze, H. K., Mearns, L. O., Navarra, A., Ojima, D. S., Riahi, K., Rosenzweig, C., Themessl, M., and Vincent, K.: The Vulnerability, Impacts, Adaptation and Climate Services Advisory Board (VIACS AB v1.0) contribution to CMIP6, Geosci. 
Model Dev., 9, 3493-3515, https://doi.org/10.5194/gmd-9-34932016, 2016

Screen, J. A. and Simmonds, I.: The central role of diminishing sea ice in recent Arctic temperature amplification, Nature, 464, 1334-1337, 2010.

Screen, J. A., Deser, C., and Simmonds, I.: Local and remote controls on observed Arctic warming, Geophys. Res. Lett., 39, L10709, https://doi.org/10.1029/2012GL051598, 2012.

Screen, J. A.: Influence of Arctic sea ice on European summer precipitation, Environ. Res. Lett., 8, 044015, https://doi.org/10.1088/1748-9326/8/4/044015, 2013.

Screen, J. A., Simmonds, I., Deser, C., and Tomas, R.: The atmospheric response to three decades of observed Arctic sea ice loss, J. Climate, 26, 1230-1248, https://doi.org/10.1175/JCLI-D-1200063.1, 2013.

Screen, J. A., Deser, C., Simmonds, I., and Tomas, R.: Atmospheric impacts of Arctic sea ice loss, 1979-2009: Separating forced change from atmospheric internal variability, Clim. Dynam., 43, 333-344, 2014.

Screen, J. A., Deser, C., and Sun, L.: Reduced risk of North American cold extremes due to continued Arctic sea ice loss, B. Am. Meteorol. Soc., 96, 1489-1503, https://doi.org/10.1175/BAMSD-14-00185.1, 2015.

Screen, J. A.: Simulated atmospheric response to regional and panArctic sea ice loss, J. Clim., 30, 3945-3962, 2017.

Screen, J. A., Deser, C., Smith, D. M., Zhang, X., Blackport, R., Kushner, P. J., Oudar, T., McCusker, K. E., and Sun, L.: Consistency and discrepancy in the atmospheric response to Arctic sea-ice loss across climate models, Nat. Geosci., 11, 155-163, https://doi.org/10.1038/s41561-018-0059-y, 2018.

Scaife, A. A., Arribas, A., Blockley, E., Brookshaw, A., Clark, R. T., Dunstone, N., Eade, R., Fereday, D., Folland, C. K., Gordon, M., Hermanson, L., Knight, J. R., Lea, D. J., MacLachlan, C., Maidens, A., Martin, M., Peterson, A. K., Smith, D., Vellinga, M., Wallace, E., Water, J., and Williams, A.: Skilful long range prediction of European and North American winters, Geophys. Res. Lett., 41, 2514-2519, https://doi.org/10.1002/2014GL059637, 2014

Schneider, D. P., Deser, C., and Fan, T.: Comparing the impacts of tropical SST variability and polar stratospheric ozone loss on the Southern Ocean westerly winds, J. Climate, 28, 9350-9372, 2015.

Schneider, D. P. and Deser, C.: Tropically driven and externally forced patterns of Antarctic sea ice change: Reconcilling observed and modeled trends, Clim. Dynam., 50, 4599-4618, https://doi.org/10.1007/s00382-017-3893-5, 2017.

Semenov, V. A. and Latif, M.: Nonlinear winter atmospheric circulation response to Arctic sea ice concentration anomalies for different periods during 1966-2012, Environ. Res. Lett., 10, 054020, https://doi.org/10.1088/1748-9326/10/5/054020, 2015.

Seierstad, I. and Bader, J.: Impact of a projected future Arctic sea ice reduction on extratropical storminess and the NAO, Clim. Dynam., 33, 937-943, https://doi.org/10.1007/s00382-008-0463-x, 2009.

Serreze, M. C., Barrett, A. P., Stroeve, J. C., Kindig, D. N., and Holland, M. M.: The emergence of surface-based Arctic amplification, The Cryosphere, 3, 11-19, https://doi.org/10.5194/tc-311-2009, 2009.
Sévellec, F., Fedorov, A. V., and Liu, W.: Arctic sea-ice decline weakens the Atlantic meridional overturning circulation, Nat Clim. Change, 7, 604-610, 2017.

Shepherd, T. G.: Effects of a warming Arctic, Science, 353, 989990, 2016.

Singarayer, J. S., Bamber, J. L., and Valdes, P. J.: Twenty-firstcentury climate impacts from a declining Arctic sea ice cover J. Climate, 19, 1109-1125, https://doi.org/10.1175/JCLI3649.1, 2006.

Smith, K. L. and Polvani, L. M.: Spatial patterns of recent Antarctic surface temperature trends and the importance of natural variability: lessons from multiple reconstructions and the CMIP5 models, Clim. Dynam., 48, 2653-2670, https://doi.org/10.1007/s00382-016-3230-4, 2017.

Smith, D. M., Dunstone, N. J., Scaife, A. A., Fiedler, E. K., Copsey, D., and Hardiman, S. C.: Atmospheric response to Arctic and Antarctic sea ice: the importance of ocean-atmosphere coupling and the background state, J. Climate, 30, 4547-4565, https://doi.org/10.1175/JCLI-D-16-0564.1, 2017.

Spielhagen, R. F., Werner, K., Sørensen, S. A., Zamelczyk, K., Kandiano, E., Budeus, G., Husum, K., Marchitto, T. M., and Hald, M.: Enhanced modern heat transfer to the arctic by warm Atlantic water, Science, 331, 450-453, 2011.

Strey, S. T., Chapman, W. L., and Walsh, J. E.: The 2007 sea ice minimum: impacts on the Northern Hemisphere atmosphere in late autumn and early winter, J. Geophys. Res., 115, D23103, https://doi.org/10.1029/2009JD013294, 2010.

Stroeve, J. C., Kattsov, V., Barrett, A., Serreze, M., Pavlova, T., Holland, M., and Meier, W. N.: Trends in Arctic sea ice extent from CMIP5, CMIP3 and observations, Geophys. Res. Lett., 39, L16502, https://doi.org/10.1029/2012GL052676, 2012.

Sun, L., Deser, C., and Tomas, R. A.: Mechanisms of stratospheric and tropospheric circulation response to projected Arctic sea ice loss, J. Clim., 28, 7824-7845, https://doi.org/10.1175/JCLI-D15-0169.1, 2015.

Sun, L., Perlwitz, J. and Hoerling, M.: What caused the recent "Warm Arctic, Cold Continents" trend pattern in winter temperatures?, Geophys. Res. Lett., 43, 5345-5352, https://doi.org/10.1002/2016GL069024, 2016.

Suo, L., Gao, Y., Guo, D., and Bethke, I.: Sea-ice free Arctic contributes to the projected warming minimum in the North Atlantic, Environ. Res. Lett., 12, 074004, https://doi.org/10.1088/17489326/aa6a5e, 2017.

Swart, N. C. and Fyfe, J. C.: The influence of recent Antarctic ice sheet retreat on simulated sea ice area trends, Geophys. Res. Lett., 40, 4328-4332, 2013.

Taylor, K. E., Williamson, D., and Zwiers, F.: The sea surface temperature and sea-ice concentration boundary conditions for AMIP II simulations, PCMDI Report No. 60, Program for Climate Model Diagnosis and Intercomparison, Lawrence Livermore National Laboratory, Livermore, California, 25 pp., 2000.

Taylor P. C., Cai, M., Hu, A., Meehl, J., Washington, W., and Zhang, G. J.: A decomposition of feedback contributions to polar warming amplification, J. Clim., 26, 7023-7043, 2013.

Thompson, D. W. J. and Solomon, S.: Interpretation of recent Southern Hemisphere climate change, Science, 296, 895-899, 2002. 
Tokinaga, H., Xie, S.-P., and Mukougawa, H.: Early 20th-century Arctic warming intensified by Pacific and Atlantic multidecadal variability, P. Natl. Acad. Sci. USA, 114, 6227-6232, 2017.

Tomas, R. A., Deser, C., and Sun, L.: The role of ocean heat transport in the global climate response to projected Arctic sea ice loss, J. Clim., 29, 6841-6859, 2016.

Turner, J., Hosking, J. S., Bracegirdle, T. J., Marshall, G. J., and Phillips, T.: Recent changes in Antarctic Sea Ice, Phil. Trans. R. Soc. A, 373, 20140163, https://doi.org/10.1098/rsta.2014.0163, 2015.

Turner, J. and Comiso, J.: Solve Antarctica's sea-ice puzzle, Nature, 547, 275-277, https://doi.org/10.1038/547275a, 2017.

Vaughan, D. G., Comiso, J. C., Allison, I., Carrasco, J., Kaser, G., Kwok, R., Mote, P., Murray, T., Paul, F., Ren, J., Rignot, E., Solomina, O., Steffen, K., and Zhang, T.: Observations: Cryosphere, in: Climate Change 2013: The Physical Science Basis, Contribution of Working Group I to the Fifth Assessment Report of the Intergovernmental Panel on Climate Change, edited by: Stocker, T. F., Qin, D., Plattner, G.-K., Tignor, M., Allen, S. K., Boschung, J., Nauels, A., Xia, Y., Bex, V., and Midgley, P. M., Cambridge University Press, Cambridge, UK, New York, NY, USA, 2013.

Vavrus, S.: The impact of cloud feedbacks on Arctic climate under greenhouse forcing, J. Clim., 17, 603-615, 2004.

Vihma, T.: Effects of Arctic sea ice decline on weather and climate: A review, Surv. Geophys., 35, 1175-1214, https://doi.org/10.1007/s10712-014-9284-0, 2014.

Walsh, J. E.: Intensified warming of the Arctic: Causes and impacts on middle latitudes, Global Planet. Change, 117, 52-63, 2014.
Webb, M. J., Andrews, T., Bodas-Salcedo, A., Bony, S., Bretherton, C. S., Chadwick, R., Chepfer, H., Douville, H., Good, P., Kay, J. E., Klein, S. A., Marchand, R., Medeiros, B., Siebesma, A. P., Skinner, C. B., Stevens, B., Tselioudis, G., Tsushima, Y., and Watanabe, M.: The Cloud Feedback Model Intercomparison Project (CFMIP) contribution to CMIP6, Geosci. Model Dev., 10, 359-384, https://doi.org/10.5194/gmd-10-359-2017, 2017.

Wu, Y. and Smith, K. L.: Response of the Northern Hemisphere midlatitude circulation to Arctic amplification in a simple atmospheric general circulation model, J. Climate, https://doi.org/10.1175/JCLI-D-15-0602.1, 2016.

Zanchettin, D., Khodri, M., Timmreck, C., Toohey, M., Schmidt, A., Gerber, E. P., Hegerl, G., Robock, A., Pausata, F. S. R., Ball, W. T., Bauer, S. E., Bekki, S., Dhomse, S. S., LeGrande, A. N., Mann, G. W., Marshall, L., Mills, M., Marchand, M., Niemeier, U., Poulain, V., Rozanov, E., Rubino, A., Stenke, A., Tsigaridis, K., and Tummon, F.: The Model Intercomparison Project on the climatic response to Volcanic forcing (VolMIP): experimental design and forcing input data for CMIP6, Geosci. Model Dev., 9, 2701-2719, https://doi.org/10.5194/gmd-9-2701-2016, 2016.

Zhang, J. L. and Rothrock, D. A.: Modeling global sea ice with a thickness and enthalpy distribution model in generalized curvilinear coordinates, Mon. Weather Rev., 131, 845-861, 2003.

Zhou, T., Turner, A. G., Kinter, J. L., Wang, B., Qian, Y., Chen, X., Wu, B., Wang, B., Liu, B., Zou, L., and He, B.: GMMIP (v1.0) contribution to CMIP6: Global Monsoons Model Inter-comparison Project, Geosci. Model Dev., 9, 3589-3604, https://doi.org/10.5194/gmd-9-3589-2016, 2016. 